\title{
Effects of Foam on Ocean Surface Microwave Emission Inferred From Radiometric Observations of Reproducible Breaking Waves
}

\author{
Sharmila Padmanabhan, Student Member, IEEE, Steven C. Reising, Senior Member, IEEE, \\ William E. Asher, Member, IEEE, L. Allen Rose, Member, IEEE, and Peter W. Gaiser, Senior Member, IEEE
}

\begin{abstract}
WindSat, the first satellite polarimetric microwave radiometer, and the NPOESS Conical Microwave Imager/Sounder both have as a key objective the retrieval of the ocean surface wind vector from radiometric brightness temperatures. Available observations and models to date show that the wind direction signal is only 1-3 K peak-to-peak at 19 and $37 \mathrm{GHz}$, much smaller than the wind speed signal. In order to obtain sufficient accuracy for reliable wind direction retrieval, uncertainties in geophysical modeling of the sea surface emission on the order of $0.2 \mathrm{~K}$ need to be removed. The surface roughness spectrum has been addressed by many studies, but the azimuthal signature of the microwave emission from breaking waves and foam has not been adequately addressed. Recently, a number of experiments have been conducted to quantify the increase in sea surface microwave emission due to foam. Measurements from the Floating Instrumentation Platform indicated that the increase in ocean surface emission due to breaking waves may depend on the incidence and azimuth angles of observation. The need to quantify this dependence motivated systematic measurement of the microwave emission from reproducible breaking waves as a function of incidence and azimuth angles. A number of empirical parameterizations of whitecap coverage with wind speed were used to estimate the increase in brightness temperatures measured by a satellite microwave radiometer due to wave breaking in the field of view. These results provide the first empirically based parameterization with wind speed of the effect of breaking waves and foam on satellite brightness temperatures at 10.8, 19, and $37 \mathrm{GHz}$.
\end{abstract}

Index Terms-Fractional area foam coverage, microwave emissivity, microwave radiometer, microwave radiometry, ocean surface, WindSat, wind speed, wind vector.

Manuscript received February 10, 2005; revised October 2, 2005. This work was supported in part by the Department of the Navy, Office of Naval Research under Awards N00014-00-1-0615 (ONR/YIP) and N00014-03-1-0044 (Space and Remote Sensing) to the University of Massachusetts Amherst, and N00014-00-1-0152 (Space and Remote Sensing) to the University of Washington. The National Polar-orbiting Operational Environmental Satellite System Integrated Program Office supported the Naval Research Laboratory's participation through Award NA02AANEG0338 and supported data analysis at Colorado State University and the University of Washington through Award NA05AANEG0153.

S. Padmanabhan and S. C. Reising are with the Microwave Systems Laboratory, Colorado State University, Fort Collins, CO 80523 USA (e-mail: spadmana@engr.colostate.edu).

W. E. Asher is with the Applied Physics Laboratory, University of Washington, Seattle, WA 98105 USA.

L. A. Rose and P. W. Gaiser are with the Remote Sensing Division, Naval Research Laboratory, Washington, DC 20375 USA.

Digital Object Identifier 10.1109/TGRS.2006.870234

\section{INTRODUCTION}

W INDSAT, the first polarimetric microwave radiometer on orbit, has as its principal objective the demonstration of retrieval of the sea surface wind vector from measured polarimetric brightness temperatures [1]. The ocean surface wind vector is one of the key environmental data records for the National Polar-orbiting Operational Environmental Satellite System (NPOESS) Conical Microwave Imager/Sounder (CMIS) instruments, first planned for launch in 2010. To date, aircraft and satellite measurements, as well as modeling results, indicate that brightness temperature variations with wind direction are small, on the order of 1-3 K peak-to-peak at 19 and $37 \mathrm{GHz}$ [2]-[5]. Therefore, quantitative knowledge of the dependence of the ocean surface emissivity on properties such as surface roughness and wave breaking is critical for wind vector retrieval. Despite the importance of this, the relationship between the microwave emission from foam and azimuth angle with respect to the wind direction is not well understood. A number of surface emission models have characterized the increase in microwave emission due to wind speed as an aggregate effect of both surface roughness and sea-foam (e.g., [6]). Since foam substantially increases ocean microwave emission [7] with a wind speed dependence that varies with different wind speed regimes, the effects of surface roughness and foam need to be considered separately.

\section{Previous Measurements}

Recent experimental investigations have provided new quantitative information on the increase in surface microwave emission due to breaking waves. In the first experiment, a $3 \mathrm{~m}$ $\times 6 \mathrm{~m}$ foam generator suspended just below a calm water surface on Chesapeake Bay produced uniform foam coverage that nearly filled the fields of view of two microwave radiometers at 10.8 and $37 \mathrm{GHz}$ [7], [8]. Radiometric measurements at incidence angles from $30^{\circ}$ to $60^{\circ}$ showed that the emissivity of foam in this experiment was greater than 0.9 at vertical polarization, and decreased with incidence angle from 0.9 to 0.75 at horizontal polarization. The foam emissivity was observed to be similar at X-band and Ka-band, at which the ratios of foam thickness to electromagnetic wavelength were observed to be 1.0 and 3.4, respectively. These measurements of foam on calm water included neither the dynamics of whitecap evolution nor the modulation due to long wave slopes during 

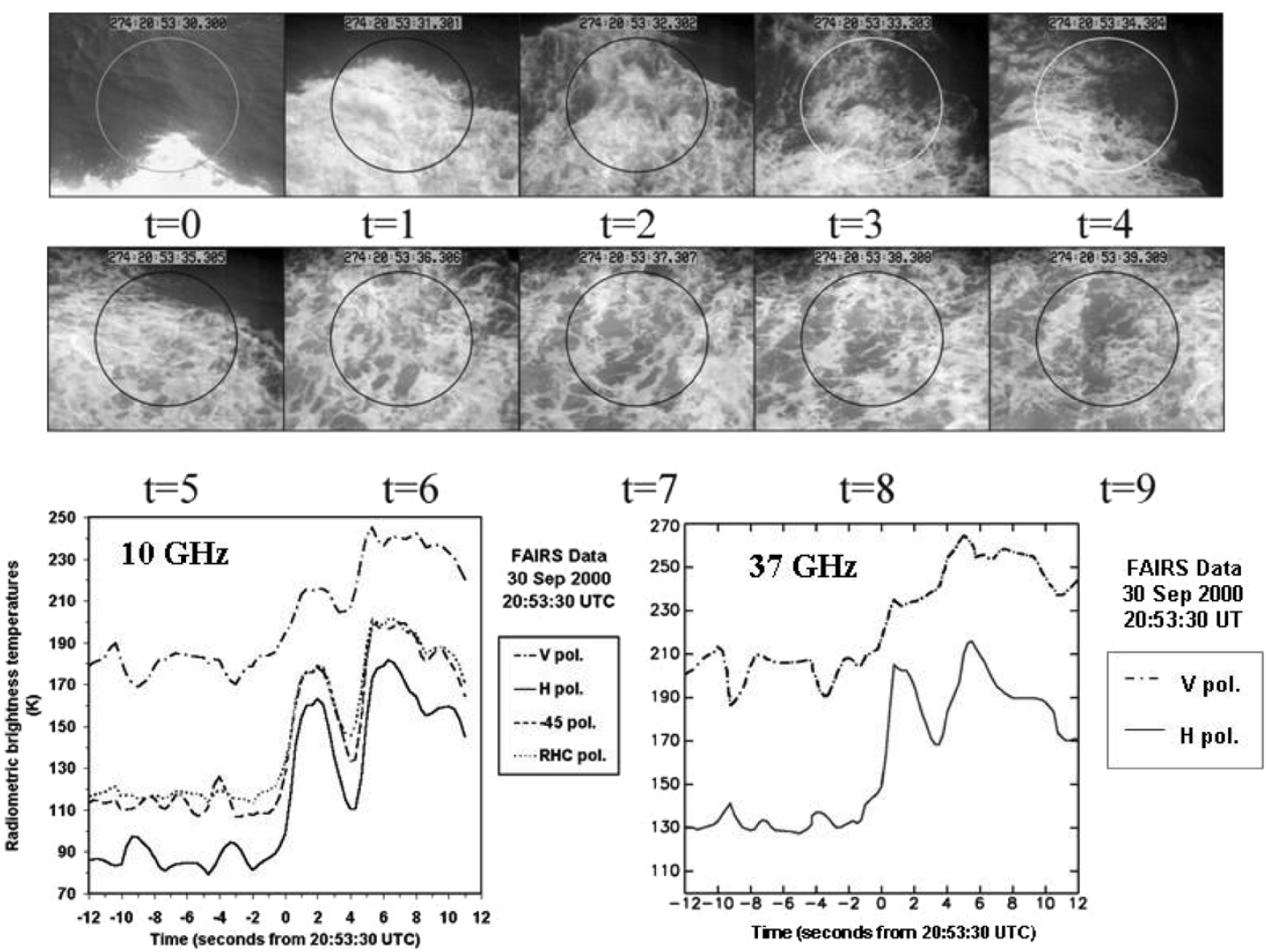

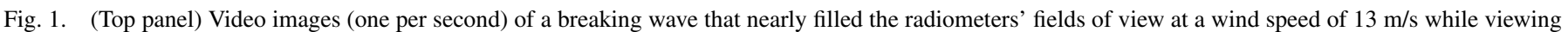

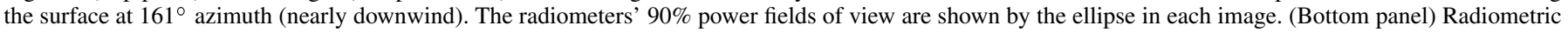
brightness temperatures at (left) X-band and (right) Ka-band during the same period. These measurements were performed during FAIRS in 2000.

wave breaking. In addition, they provided no information on the dependence of foam emissivity or of whitecap coverage in the field of view on azimuth angle with respect to the direction of wave breaking.

The need to improve retrieval of wind speed and direction from WindSat and the upcoming NPOESS CMIS through more accurate forward modeling of sea surface emission, as well as to study the effects of air-sea interactions, motivated the passive microwave component of the Fluxes, Air-Sea Interaction and Remote Sensing (FAIRS) Experiment [9]-[11]. The FAIRS experiment was conducted from the U.S. Navy's FLoating Instrumentation Platform (R/P FLIP) in free-drift mode for 27 days in the fall of 2000 in the northeastern Pacific Ocean, starting at $36.96^{\circ} \mathrm{N}, 123.60^{\circ} \mathrm{W}$ and ending at $34.83^{\circ} \mathrm{N}, 123.25^{\circ} \mathrm{W}$. Passive polarimetric observations were performed from the R/P FLIP at wind speeds of up to $16 \mathrm{~m} / \mathrm{s}$ with concomitant large-scale breaking waves.

Fig. 1 shows a sequence of sea surface images recorded at 1 frame/s during FAIRS using a video imager boresighted with $\mathrm{X}$-band $(10.8 \mathrm{GHz})$ and $\mathrm{Ka}$-band $(37 \mathrm{GHz})$ microwave radiometers aimed at an incidence angle of $53^{\circ}$ and an azimuth angle of $161^{\circ}$ with respect to the wind, at a wind speed of $13 \mathrm{~m} / \mathrm{s}$. The images show the development of this breaking wave over $10 \mathrm{~s}$. After the wave breaks between $t=0 \mathrm{~s}$ and $t=1 \mathrm{~s}$, the decaying bubble plume moves back and forth in the two radiometers' fields of view, which are similar to each other and have been approximated by an average field of view in the video im- ages in Fig. 1. At $t=4 \mathrm{~s}$ the field of view is only partially covered by foam, accompanied by a decrease in radiometric brightness temperatures. Subsequently, the plume fills nearly the entire field of view $(t=5 \mathrm{~s})$ again, resulting in greater radiometric brightness temperatures at all polarizations than during active breaking at $t=0$ to $2 \mathrm{~s}$. A similar sequence of video images and corresponding brightness temperatures were measured at an incidence angle of $45^{\circ}$ and an azimuth angle of $281^{\circ}$ (not shown). Unlike the first case observed (downwind, $53^{\circ}$ incidence), in this case (crosswind, $45^{\circ}$ incidence), brightness temperatures during the active wave breaking were greater than those during the decaying bubble plume.

The data from FAIRS indicate that emission due to foam depends on the incidence and azimuth angles of observation. Near-surface measurements provide the capability to distinguish changes in sea surface emission caused by breaking waves and foam from changes resulting from other factors. However, it was also found that the temporal intermittency and spatial variability of breaking waves on the open ocean make it difficult to acquire reproducible measurements of beam-filling foam at close range. Reproducible near-surface measurements are therefore necessary to form quantitative conclusions about the observation angle dependence of emission due to breaking waves. Understanding how breaking waves and foam affect microwave emissivity as a function of wind speed and observation angle is critical to improving retrieval of wind direction from passive polarimetric microwave observations. 


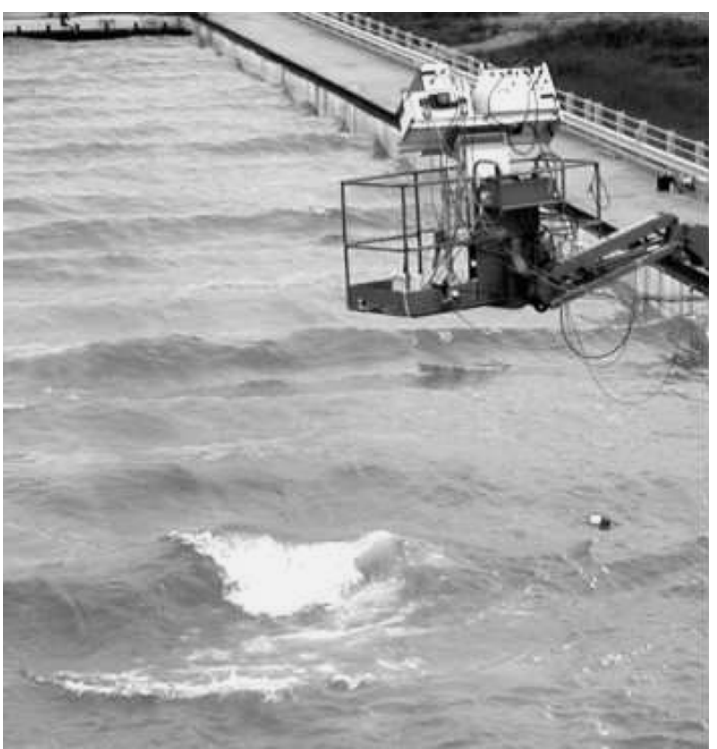

Fig. 2. Microwave radiometers observing a breaking wave at the WindSat polarimetric frequencies $(10.7,18.7$, and $37 \mathrm{GHz})$ during the POEWEX'02 Experiment at the OHMSETT wave basin.

\section{EXPERIMENT DESCRIPTION}

Because of the inherent difficulties of near-surface radiometric measurements on the open ocean, systematic measurements of the microwave emission of reproducible breaking waves were performed in a wave basin. This experiment, the Polarimetric Observations of the Emissivity of Whitecaps Experiment (POEWEX'02), was conducted during October 2002 at the OHMSETT wave basin in Leonardo, NJ [12]. OHMSETT is a $200 \mathrm{~m}$ long $\times 20 \mathrm{~m}$ wide $\times 2.4 \mathrm{~m}$ deep wave basin filled with saltwater at a salinity of $35 \mathrm{ppt}$. A shoal, or beach, was installed in the wave basin that caused waves to break in the same location every 1-2 s, as shown in Fig. 2. The water depth at the beach was $45 \pm 1 \mathrm{~cm}$. The wave basin is also equipped with two instrument carriages spanning the width of the tank that can be traversed along its length. As described in detail below, these carriages were used for mounting an underwater video camera, capacitance void fraction probe, and acoustic Doppler velocimeters. For radiometric measurements, microwave radiometers were mounted in the basket of a boom-lift crane so that they could be positioned to view the water surface at a range of incidence and azimuth angles. For this experiment, the $0^{\circ}$ azimuth angle was defined as looking into the direction of wave propagation, and $180^{\circ}$ as viewing along the direction of wave propagation, as shown in Fig. 3.

Fractional foam coverage in the radiometers' fields of view was measured from digital video images recorded simultaneously using a bore-sighted Spektrum M1342 1/3" format monochrome charge-coupled device (CCD) video camera. The Pelco 5-40-mm telephoto zoom lens on the camera was set to provide an angular field of view of $20^{\circ}$ in the horizontal, leading to a nadir image size of about $4 \mathrm{~m} \times 3 \mathrm{~m}$ at a range of $12 \mathrm{~m}$. The analog video output from the camera was digitized at a rate of 4 frames/s using a Data Translation DT3152 monochrome frame grabber and custom acquisition software. In order to permit synchronization of the radiometer data and the video images, each

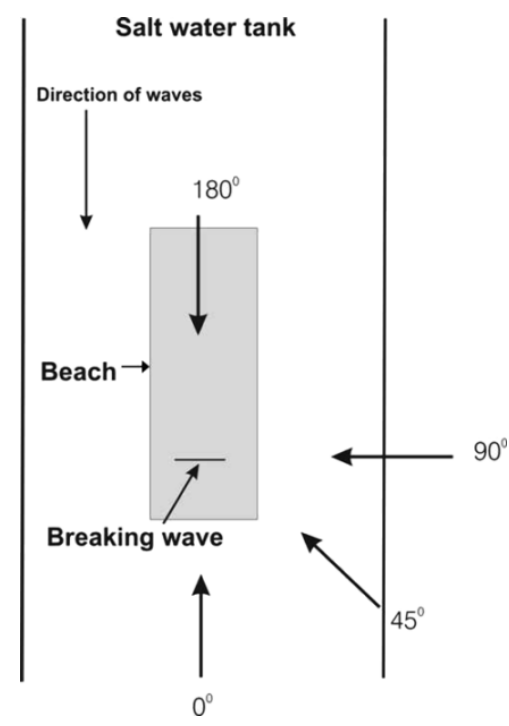

Fig. 3. Four azimuthal viewing directions of the radiometers.

video image was stamped with a time code read from a TrueTime 560-5901 GPS-PCI card mounted in the same computer as the DT3152.

The fractional area foam coverage in the field of view of the radiometers was found by analyzing the bore-sighted video measurements using the grayscale method of Asher and Wanninkhof [13]. This involves measuring the fraction of pixels in the field of view of the antenna that exceed the brightness threshold distinguishing the breaking wave from the water background. The resulting fractional area foam coverage may include both actively breaking crests and decaying bubble plumes. In this paper, the result is called the foam fraction for brevity. The top frame of Fig. 4 shows a typical image of a breaking wave in the wave basin taken at an azimuth angle of $90^{\circ}$ and an incidence angle of $53^{\circ}$. The lower frame of Fig. 4 shows the resulting binary image with all foam-covered pixels in white for a brightness threshold of 0.7 out of a grayscale range of 0 to 1.0 .

The bubble size spectrum was characterized using a Cohu $21201 / 2^{\prime \prime}$ format monochrome CCD video camera mounted in a custom-designed underwater housing. The camera was set to use an electronic shutter speed of $1 / 10000 \mathrm{~s}$, and the lens was a Computar TEC-M55 55-mm telecentric macro zoom lens set to provide a field of view of $13.7 \mathrm{~mm} \times 10.5 \mathrm{~mm}$ at the front window of the video housing. This corresponded to a pixel size of $21 \mu \mathrm{m} \times 21 \mu \mathrm{m}$. The camera housing was mounted on one of the traversing instrument carriages at a depth of $12 \mathrm{~cm}$ below the calm water surface. In order to avoid measuring bubbles generated by flow past the housing itself, bubble size spectra were acquired by traversing the camera through the breaking zone at a speed of approximately $5 \mathrm{~cm} / \mathrm{s}$. Ambient lighting was used, resulting in images of bubbles that were not possible to size accurately using an automated sizing algorithm. Therefore, a bubble size spectrum was derived by manually sizing and counting bubbles in 102 video frames taken at $0.25 \mathrm{~s}$ intervals as the camera swept through the zone of wave breaking.

Void fraction, or the volume of air entrained by the breaking wave per unit volume of water, was measured using capacitance probes based on the design reported by Lamarre and Melville [14]. These probes measure the total volume of air entrained 

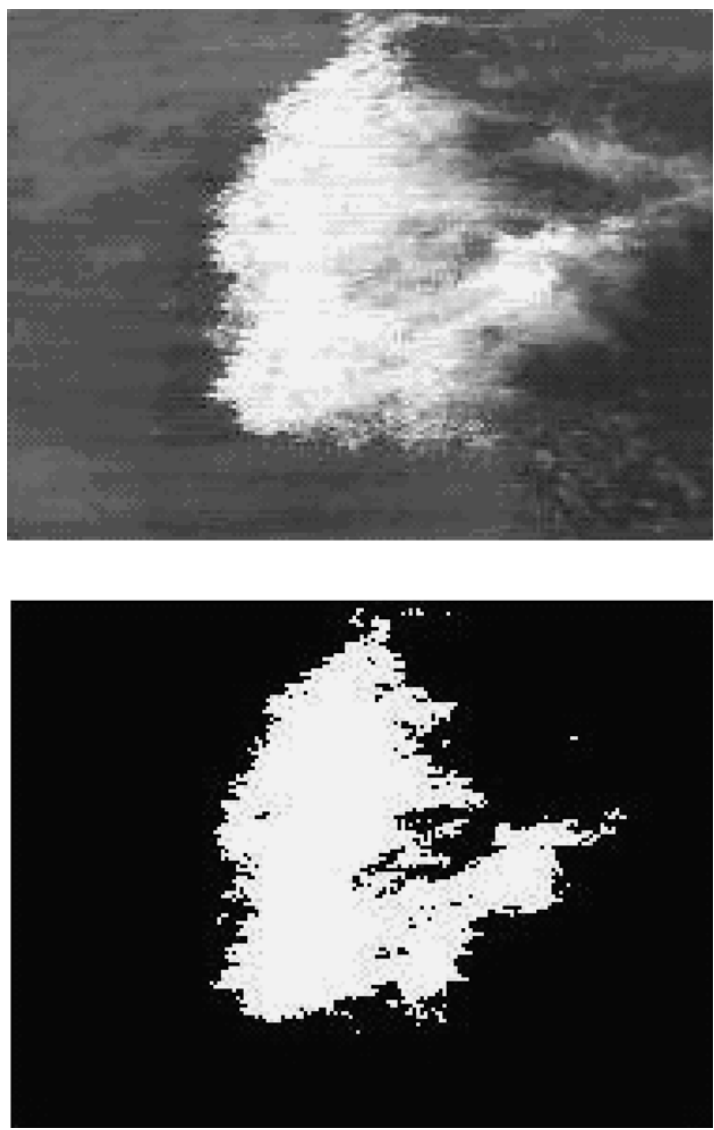

Fig. 4. (Top) Typical image of breaking wave at the OHMSETT wave basin digitized using the camera and frame grabber described in the text. (Bottom) Binary image showing area taken to be foam covered at a brightness threshold of 0.7. Image was recorded at an azimuth angle of $90^{\circ}$ and an incidence angle of $53^{\circ}$.

by the breaking waves by measuring the change in capacitance of seawater between two electrodes mounted $10 \mathrm{~cm}$ apart. Two probes were mounted in the wave basin, one on the moving bridge with the underwater camera at a depth of $12 \mathrm{~cm}$ below the calm water surface and the other on the centerline of the beach at a mean depth of $35 \mathrm{~cm}$ below the calm water surface. The void probes were calibrated in saltwater using a bubble column tank. In the calibration tank, the total void fraction was measured by determining the mean water surface elevation change as compressed air was blown through gas permeable tubing coiled in the tank bottom.

In order to measure temporal stability of the wave field over a particular measurement time and to compare day-to-day variations in the wave field, wave heights were measured at three locations in the wave basin using three Omega Engineering pressure transducers (two Model PX439-002 and one Model PX438-005). Two pressure sensors were mounted on the beach centerline at mean water depths of $45 \mathrm{~cm}$ (in the breaking zone) and of $91 \mathrm{~cm}$ (before the waves began to break). The other pressure sensor was mounted on the instrument carriage below the underwater video camera housing at a depth of approximately $55 \mathrm{~cm}$. Each pressure transducer was a current source, the output of which was converted to a voltage using a $436-\Omega$ precision resistor. Subsurface turbulence was measured using two Sontek LabADV acoustic-Doppler velocimeters (ADVs) mounted at depths of 20 and $35 \mathrm{~cm}$ on the instrument carriage with the underwater camera and void probe. Analysis of these data was greatly complicated by the presence of bubbles and is beyond the scope of this paper. Relative changes in the small-scale roughness features of the water surface were measured using a 14-GHz scatterometer mounted at an incidence angle of $70^{\circ}$. The scatterometer was mounted on the instrument carriage holding the ADVs, underwater camera, and void probe. However, its field of view for most of the experiment was immediately behind the main breaking zone, where small-scale roughness was greatly affected by the decaying bubble plumes. As in the case of the data from the ADVs, the discussion of the scatterometer data is beyond the scope of this paper.

The analog voltage outputs of both void fraction probes and of the three pressure transducers were digitized using a DT321 16-bit analog-to-digital converter and custom data acquisition software at a rate of $500-\mathrm{Hz}$ per channel. This raw void probe data was then digitally low-pass filtered with a cutoff frequency of $25 \mathrm{~Hz}$ to reduce noise. Processing of the pressure transducer data is described in detail below. The analog data stream was synchronized with the video data by passing an IRIG-B time code from the TrueTime GPS-PCI card in the video acquisition computer to a TrueTime 560-5900 PCI-SG card in the data acquisition computer. The IRIG-B time code sent to the PCI-SG card was read at the beginning of each data collection.

The raw time-series from the pressure transducers were digitally low-pass filtered using a sixth-order Chebyshev filter with a $-20 \mathrm{~dB}$ point of $20 \mathrm{~Hz}$. The edge of the filter stop band was chosen to be an order of magnitude larger than the highest frequency waves that could be measured by the transducers. The data records from the pressure transducers required correction for the effects of the dynamic pressure of the propagating waves as discussed by Dean and Dalrymple [15]. Specifically, this involved calculating the pressure response factor, $K_{P}$, for each transducer using the relation

$$
K_{P}=\frac{\cosh (k(h-z))}{\cosh (k h)}
$$

where $k$ is the wavenumber of the dominant wave in the tank, and $h$ is the water depth at the transducer. This wavenumber $k$ is estimated from the dominant wavelength $L$, as $2 \pi / L$ where $L$ is derived by solving

$$
L=\frac{g}{2 \pi} T^{2} \tanh \left(\frac{2 \pi h}{L}\right)
$$

where $g$ is the acceleration due to gravity, and the spectral estimates of the dominant wave frequency were used to derive the wave period $T$. Using the wave height time-series that had been corrected using $K_{P}$ from (1), average power spectra were calculated by segmenting the time-series for a particular pressure gauge into subrecords that were $40.96 \mathrm{~s}$ long, calculating the power spectrum for each subrecord, and then summing the power spectra and averaging. The time-series of corrected water surface elevation, $\eta(t)$, could then be computed from the pressure record as

$$
\eta(t)=\frac{p(t)-\rho g z}{\rho g K_{P}}
$$

where $\rho$ is the density of seawater and $z$ is the depth of the pressure sensor below the mean water level. All time-series calcula- 
TABLE I

X-, K-, AND Ka-BAND RADIOMETER PARAMETERS

\begin{tabular}{|c|c|c|c|}
\hline Parameter & X-band & K-band & Ka-band \\
\hline Center Frequency & $10.8 \mathrm{GHz}$ & $18.7 \mathrm{GHz}$ & $36.5 \mathrm{GHz}$ \\
\hline 3 dB Beamwidth & $7^{\circ}$ & $7^{\circ}$ & $7^{\circ}$ \\
\hline Bandwidth & $500 \mathrm{MHz}$ & $200 \mathrm{MHz}$ & $250 \mathrm{MHz}$ \\
\hline Radiometric Sensitivity at 1 sec Integration Time & $0.16 \mathrm{~K}$ & $0.15 \mathrm{~K}\left(\Delta \mathrm{G} / \mathrm{G}=3 \times 10^{-4}\right)$ & $0.15 \mathrm{~K}\left(\Delta \mathrm{G} / \mathrm{G}=3 \times 10^{-4}\right)$ \\
\hline Absolute Accuracy & $\sim 3 \mathrm{~K}$ & $\sim 1 \mathrm{~K}$ & $\sim 1 \mathrm{~K}$ \\
\hline Antenna Side Lobe Level & $\sim 25 \mathrm{~dB}$ & $\sim 25 \mathrm{~dB}$ & $\sim 25 \mathrm{~dB}$ \\
\hline Antenna Main Beam Efficiency & $95 \%$ & $95 \%$ & $95 \%$ \\
\hline
\end{tabular}

tions were performed in Matlab V11.1 (The Mathworks, Natick, MA) using the Matlab Signal Processing Toolbox.

These in situ measurements of foam, roughness, and wave properties are needed for intercomparison of electromagnetic models of emission and scattering from foam, as in Chen et al. [8]. They also provide assurance that the physical properties of the waves in the basin are similar to properties of breaking waves on the ocean surface.

\section{RADIOMETRIC MEASUREMENTS}

Radiometric measurements were performed within the WindSat polarimetric frequency bands [1] at X-band $(10.8 \mathrm{GHz}), \mathrm{K}-\mathrm{band}(18.7 \mathrm{GHz})$, and Ka-band $(37 \mathrm{GHz})$. The operating characteristics of the three microwave radiometers are listed in Table I.

The radiometers operating at 18.7 and $37 \mathrm{GHz}$ were Dicke-switched and measured at horizontal and vertical polarization. The Naval Research Laboratory 10.8-GHz polarimetric radiometer was total power and measured at horizontal, vertical, $+45^{\circ}$ linear, $-45^{\circ}$ linear, left-hand circular, and right-hand circular polarizations. Brightness temperatures were measured for calm water (no waves produced) and for breaking waves. Fig. 3 shows the azimuth angles of observation during POEWEX'02, i.e., $0^{\circ}, 45^{\circ}, 90^{\circ}$, and $180^{\circ}$ with respect to the direction of wave breaking. At each azimuth angle, brightness temperatures were measured at incidence angles of $45^{\circ}, 53^{\circ}$, and $60^{\circ}$. The radiometers were positioned so that the slant range to the water surface was constant at $12 \mathrm{~m}$.

External calibration measurements using liquid nitrogen and ambient loads were performed before and after each azimuth angle measurement. Tipping curves were measured to use the cosmic background radiation as a stable cold reference temperature. In the $\mathrm{K}$ - and Ka-band radiometers, internal calibration was performed every $45 \mathrm{~s}$ by measuring internal noise sources and matched loads to correct for gain and offset fluctuations due to unavoidable small changes in the physical temperature of the systems. The $\mathrm{X}$-band radiometer performed internal calibrations by viewing two internal loads, one at the ambient temperature of the radiometer and one that was cooled by a thermoelectric cooler. Calm water observations were performed before each set of breaking wave measurements to validate the calibration by comparing the measured data with the Klein and Swift [16] and Ellison et al. [17] models of calm water emissivity. For all surface measurements, the self-emission of the surface was found by subtracting the reflected atmospheric downwelling radiation from the measured antenna temperature using the method described by Rose et al. [7]. The measured brightness temperatures compared well with the models, as shown in Figs. 5 and 6.

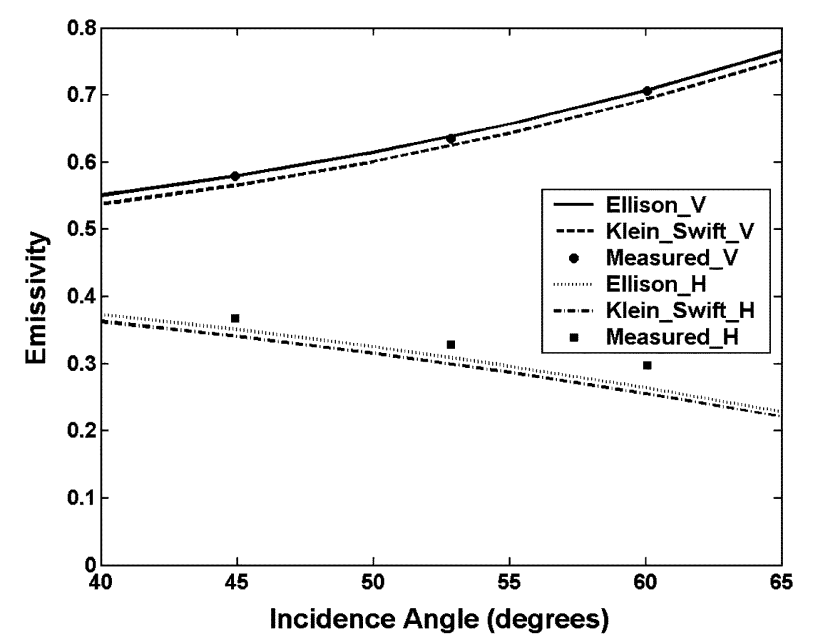

Fig. 5. Calm water emissivity at H-pol and V-pol, calculated from antenna temperature measurements at $37 \mathrm{GHz}$, compared with the Klein-Swift and Ellison models.

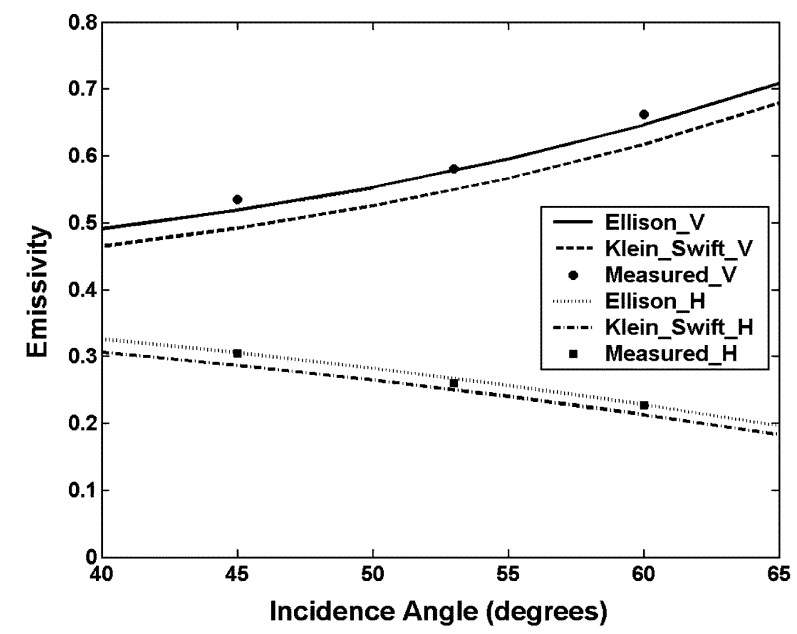

Fig. 6. Calm water emissivity at H-pol and V-pol, calculated from antenna temperature measurements at $18.7 \mathrm{GHz}$, compared with the Klein-Swift and Ellison models.

When the Earth's surface is observed by a microwave radiometer at close range, the radiation at the antenna aperture is the sum of the surface emission and the radiation from the atmosphere that is scattered, or reflected with a reflection coefficient less than one, from the surface. For the purposes of this analysis, the "reflected" sky radiation is given to first order by the surface reflectivity, i.e., one minus the emissivity, times the downwelling sky radiation. In this experiment, the slant range of the radiometer is only $12 \mathrm{~m}$, so both the upwelling emission of the atmosphere and the atmospheric attenuation from the surface to the radiometer antenna can be ignored. 
A breaking wave covering a fraction of the field of view, $f$, may include both actively breaking crests and decaying bubble plumes. The measured antenna temperature when viewing a breaking wave with maximum (of time-series) foam fraction $f_{1}$ is

$$
\begin{aligned}
T_{A, \mathrm{BW}}= & \eta\left\{f_{1}\left[\epsilon_{\text {foam }} T_{W}+\left(1-\epsilon_{\text {foam }}\right) T_{A, \mathrm{SKY}}\right]+\left(1-f_{1}\right)\right. \\
& \left.\times\left[\epsilon_{\text {rough_water }} T_{W}+\left(1-\epsilon_{\text {rough_water }}\right) T_{A, \mathrm{SKY}}\right]\right\} \\
+ & (1-\eta) T_{\mathrm{BACK}} .
\end{aligned}
$$

The antenna temperature when viewing a water surface with minimum (of time-series) foam fraction $f_{2}$ between breaking waves can be expressed as

$$
\begin{aligned}
T_{A, W}= & \eta\left\{f_{2}\left[\epsilon_{\text {foam }} T_{W}+\left(1-\epsilon_{\text {foam }}\right) T_{A, \mathrm{SKY}}\right]+\left(1-f_{2}\right)\right. \\
& \left.\times\left[\epsilon_{\text {rough_water }} T_{W}+\left(1-\epsilon_{\text {rough_water }}\right) T_{A, \mathrm{SKY}}\right]\right\} \\
+ & (1-\eta) T_{\mathrm{BACK}}
\end{aligned}
$$

where

\section{$T_{A, \mathrm{SKY}}$ \\ $T_{A, \mathrm{BW}}$}

$f_{1}$

$T_{A, W}$

$f_{2}$

$\epsilon_{\text {foam }}, \epsilon_{\text {rough_water }}$

$T_{W}$

$\eta$

$(1-\eta) T_{\mathrm{BACK}}$

$T_{\mathrm{BACK}}$ brightness temperature of downwelling sky radiation;

maximum value of antenna temperature when the breaking wave is in the field of view;

foam fraction when antenna temperature is at its maximum value;

minimum value of antenna temperature, i.e., when the surface in the field of view is almost entirely rough water; foam fraction when antenna temperature is at its minimum value;

emissivities of foam and rough water, respectively;

physical temperature of the water, which was measured to be $290 \mathrm{~K}$ during the experiment;

fraction of the contribution to $T_{A}$ from the $90 \%$ power field of view of the antenna;

contribution to $T_{A}$ from outside the $90 \%$ power field of view of the antenna; brightness temperature of the scene outside the $90 \%$ power field of view of the antenna, which is taken to be the same as the brightness temperature of rough water with no foam.

Solving (4) and (5) for $\epsilon_{\text {foam }}$ and $\epsilon_{\text {rough_water }}$ leads to

$$
\begin{aligned}
\epsilon_{\text {foam }}= & \frac{\left(1-f_{2}\right)\left(T_{A, \mathrm{BW}}-\eta T_{A, \mathrm{SKY}}\right)}{\eta\left(f_{1}-f_{2}\right)\left(T_{W}-T_{A, \mathrm{SKY}}\right)} \\
& -\frac{\left(1-f_{1}\right)\left(T_{A, W}-\eta T_{A, \mathrm{SKY}}\right)}{\eta\left(f_{1}-f_{2}\right)\left(T_{W}-T_{A, \mathrm{SKY}}\right)} \\
& -\left(\frac{1-\eta}{\eta}\right)\left(\frac{T_{\mathrm{BACK}}}{T_{W}-T_{A, \mathrm{SKY}}}\right) \\
\epsilon_{\text {rough_water }}= & \frac{\left(f_{1}\right)\left(T_{A, W}-\eta T_{A, \mathrm{SKY}}\right)}{\eta\left(f_{1}-f_{2}\right)\left(T_{W}-T_{A, \mathrm{SKY}}\right)} \\
& -\frac{\left(f_{2}\right)\left(T_{A, \mathrm{BW}}-\eta T_{A, \mathrm{SKY}}\right)}{\eta\left(f_{1}-f_{2}\right)\left(T_{W}-T_{A, \mathrm{SKY}}\right)} \\
& -\left(\frac{1-\eta}{\eta}\right)\left(\frac{T_{\mathrm{BACK}}}{T_{W}-T_{A, \mathrm{SKY}}}\right)
\end{aligned}
$$

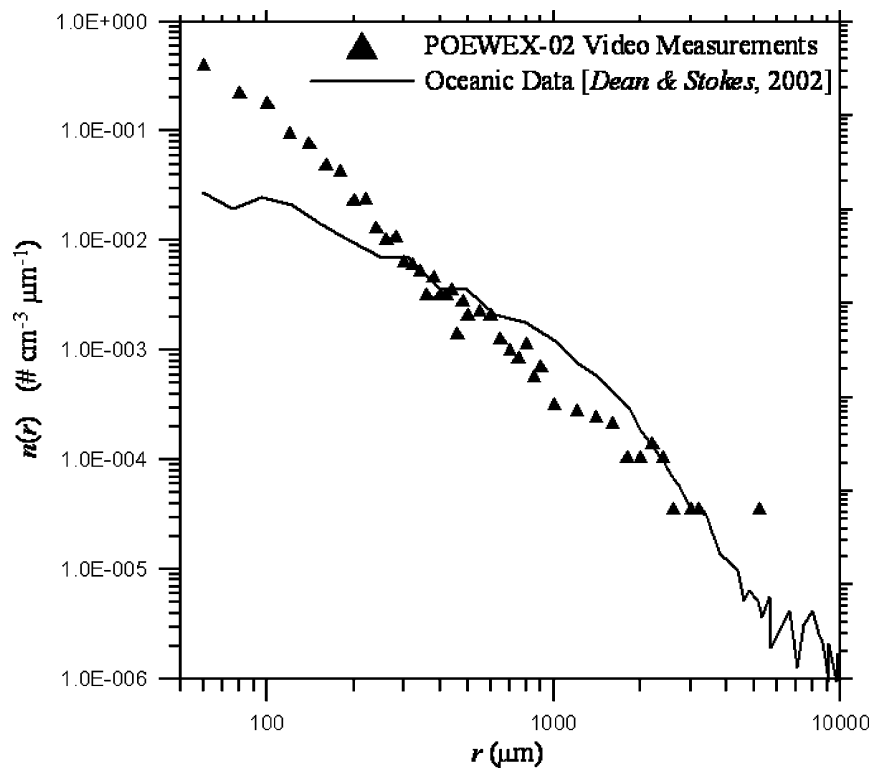

Fig. 7. Bubble size spectrum measured in the OHMSETT wave basin using the underwater video camera system described in the text. Also shown are the bubble concentrations measured by Deane and Stokes [18] in the core of breaking waves on the open ocean.

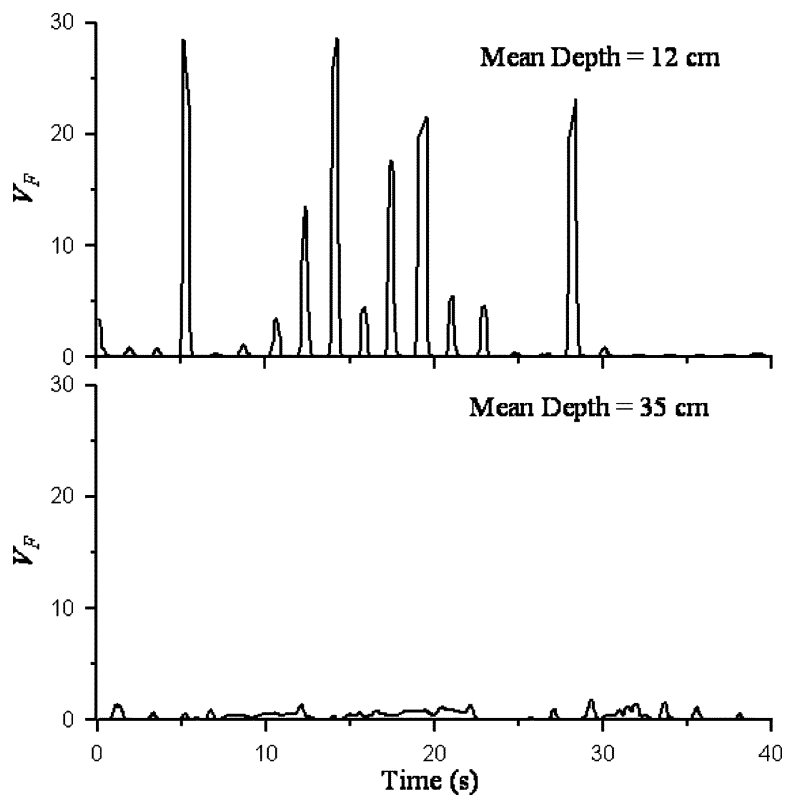

Fig. 8. Void fraction (expressed as a percentage) measured at two different depths in the OHMSETT wave basin in the core of the breaking waves. The top time-series shows the data from the shallow probe mounted on the instrument carriage, and the bottom time-series is from the deeper probe mounted on the beach.

$$
\epsilon_{\text {foam }}-\epsilon_{\text {rough_water }}=\frac{T_{A, \mathrm{BW}}-T_{A, W}}{\eta\left(f_{1}-f_{2}\right)\left(T_{W}-T_{A, \mathrm{SKY}}\right)} .
$$

We have used (6a) and (6b) to calculate the emissivity of breaking waves and foam using in situ measurements of $T_{W}$ and radiometric measurements of $T_{A, W}, T_{A, \mathrm{BW}}$ and $T_{A, \mathrm{SKY}}$, as well as $f_{1}$ and $f_{2}$ obtained from video imagery.

\section{EXPERIMENTAL RESULTS}

The physical measurements were used to verify that the gross features of breaking waves in the wave basin were similar to those of breaking waves on the open ocean. Fig. 7 shows the 


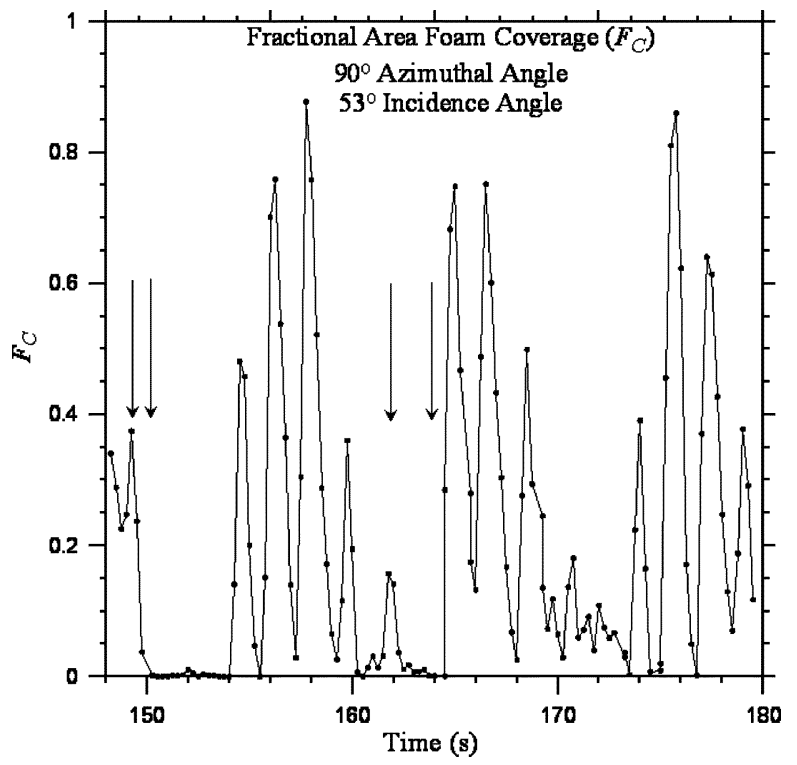

Fig. 9. Short time-series of fractional area foam coverage, $F_{c}$, measured in the wave basin using the surface video camera at an azimuth angle of $90^{\circ}$ and an incidence angle of $53^{\circ}$

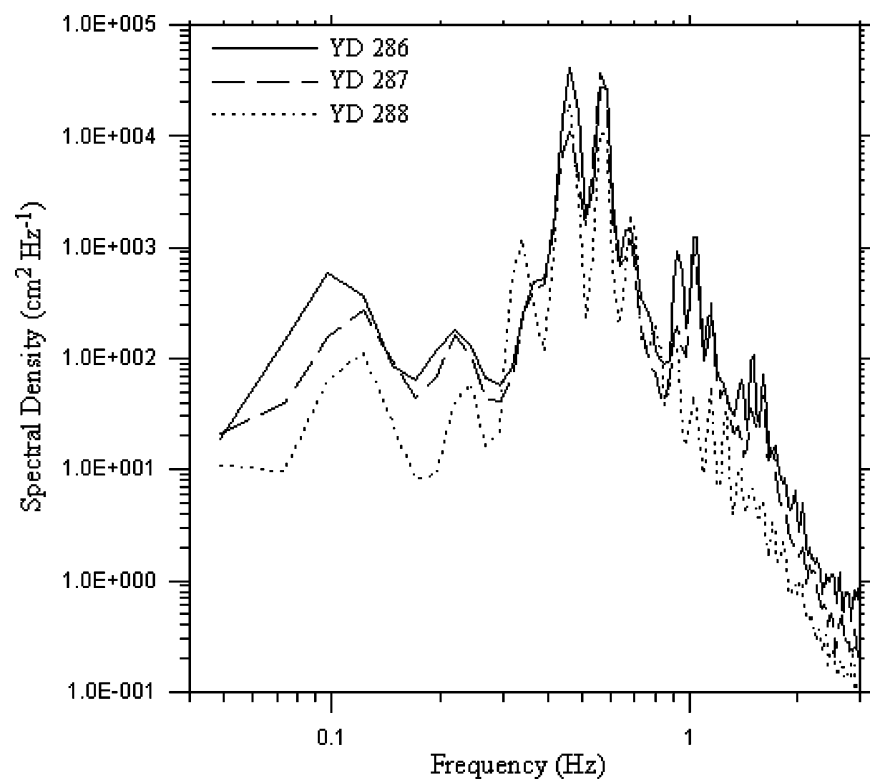

Fig. 10. Power spectral density estimates showing the frequency content of the wave height time-series measured by a pressure transducer mounted at a depth of $91 \mathrm{~cm}$.

bubble size spectrum measured in the wave basin compared to a bubble size spectrum reported by Deane and Stokes [18]. There is excellent agreement between the two datasets over the size range of $0.3-3 \mathrm{~mm}$, suggesting that the bubble populations generated by breaking waves in the wave basin were realistic in comparison to those on the open ocean. Similarly, Fig. 8 shows two time-series of void fraction, $V_{F}$, measured by the two void probes. The probes show the expected decrease in $V_{F}$ with increasing depth, but more importantly, the maximum value measured by the shallow probe, i.e., $25 \%$ to $30 \%$, agrees well with previous measurements made by Lamarre and Melville [19] and Deane [20]. The agreement in bubble size spectrum and the similarity in void fraction between the breaking waves in OHMSETT and those on the ocean suggests that the radiometric prop-

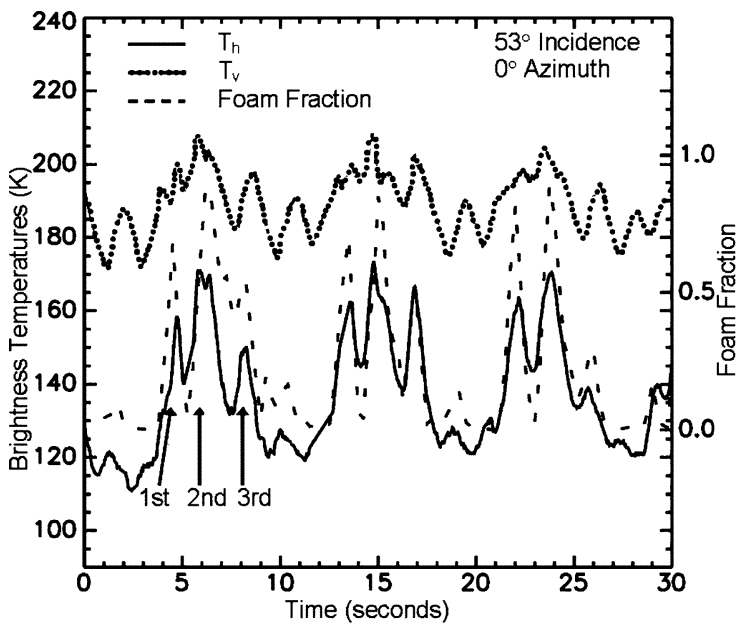

Fig. 11. Radiometric brightness temperature at $18.7 \mathrm{GHz}$ measured at an azimuth angle of $0^{\circ}$ (looking into the direction of breaking) and at an incidence angle of $53^{\circ}$ during POEWEX'02. Groups of three breaking waves are observed, similar to Fig. 9.

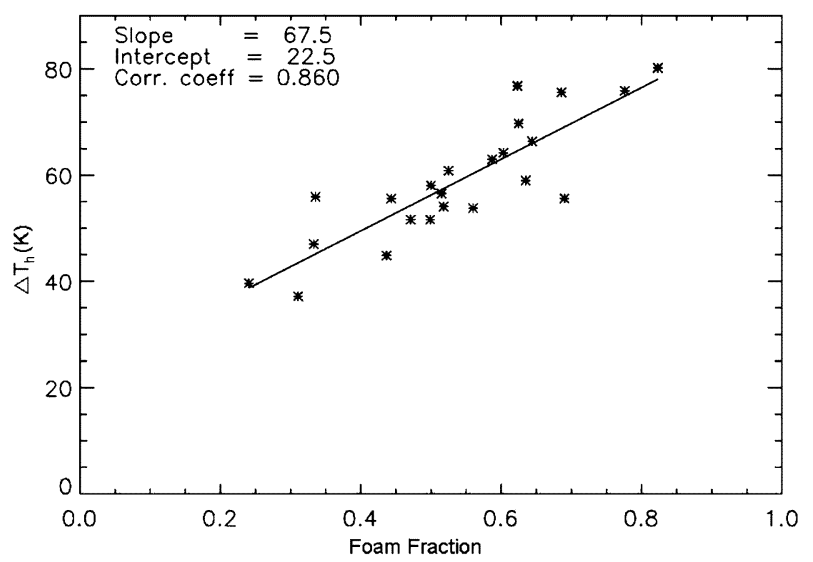

Fig. 12. Correlation of change in horizontal brightness temperature with whitecap coverage in the field of view at $18.7 \mathrm{GHz}$, for only the first breaking wave in each group.

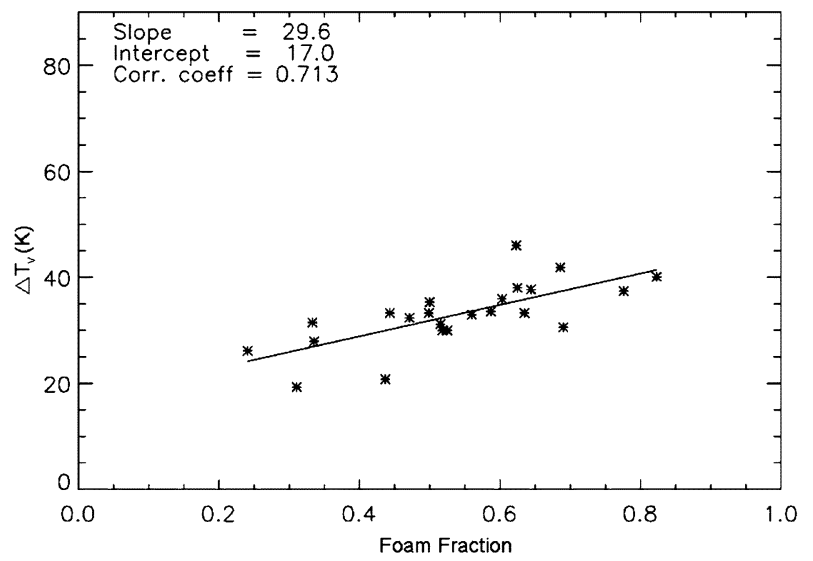

Fig. 13. Correlation of change in vertical brightness temperature with whitecap coverage in the field of view at $18.7 \mathrm{GHz}$, for only the first breaking wave in each group.

erties measured here would be similar to radiometric properties measured for breaking waves in the ocean.

Fig. 9 is a short time-series of fractional area foam coverage, $F_{C}$ (i.e., the portion of the water surface covered by breaking 
$53^{\circ}$ Incidence, $0^{\circ}$ Azimuth

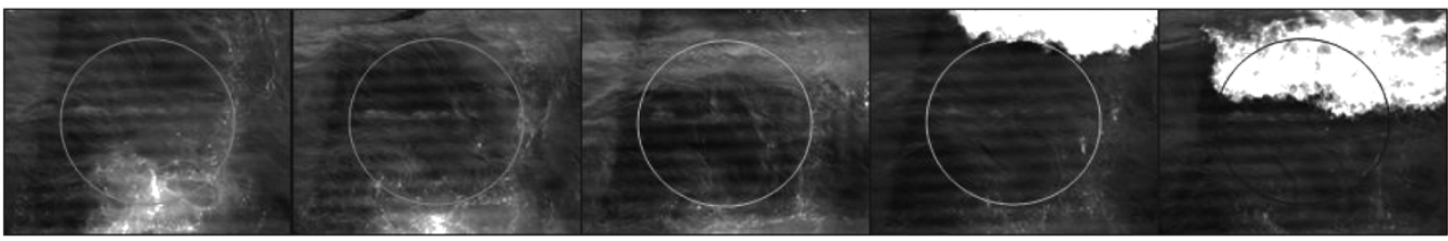

$\mathbf{t}=\mathbf{0}$

$\mathbf{t}=\mathbf{0 . 5}$

$\mathbf{t}=1$

$t=1.5$

$\mathbf{t}=\mathbf{2}$

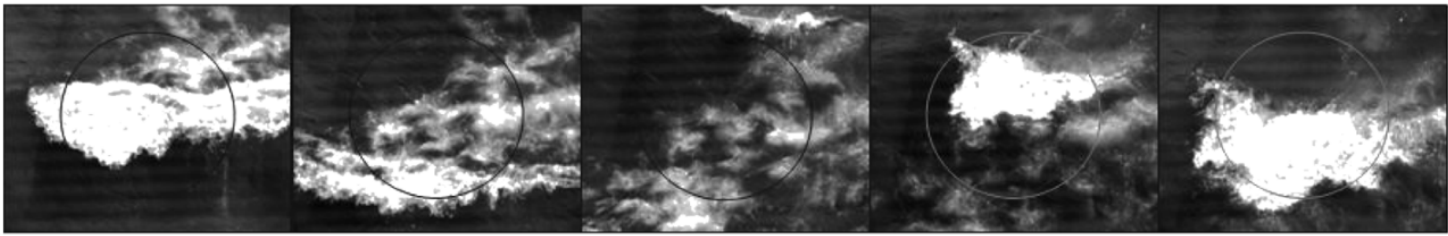

$\mathbf{t}=\mathbf{2 . 5}$

$\mathbf{t}=\mathbf{3}$

$t=3.5$

$18.7 \mathrm{GHz}$
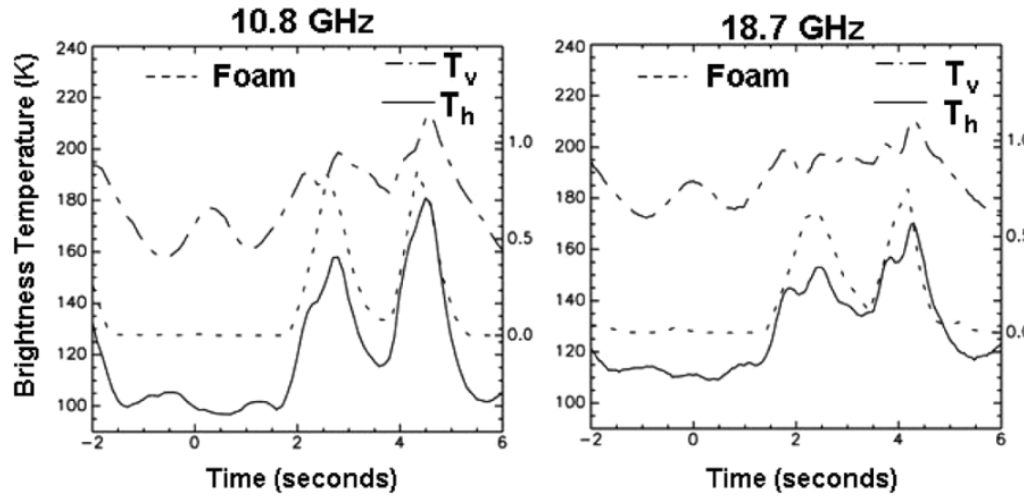

$\mathbf{t}=\mathbf{4}$

$\mathrm{t}=\mathbf{4 . 5}$

$36.5 \mathrm{GHz}$

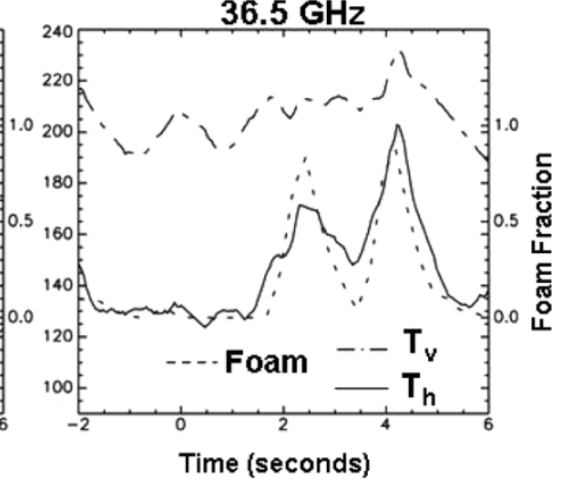

Fig. 14. (Top panel) Time-series of video images at a rate of 2 frames/s with the boresighted radiometer's field of view shown by an ellipse. These measurements were performed at an azimuth angle of $0^{\circ}$ and an incidence angle of $53^{\circ}$. (Bottom panel) Time-series of (dashed-dotted line) vertical and (solid line) horizontal brightness temperatures as well as (dashed line) whitecap coverage in the field of view, at frequencies of 10.8, 18.7, and $37 \mathrm{GHz}$. The $t=0$ on the lower time axes corresponds to the time of the top left video image.

waves, stable foam patches, and dense bubble plumes, equivalent to whitecap coverage on the open ocean) measured using the video camera in the OHMSETT tank at an azimuth angle of $90^{\circ}$ and an incidence angle of $53^{\circ}$. The detailed structure typical of the wave field is clearly seen with the grouping behavior of the breaking waves. The two sets of vertical arrows denote the beginning and end of time-series segments that were used to estimate the mean decay time of the bubble plumes. Selecting 20 such segments showed that the decay time constant of the foam fraction ranged from approximately $0.15-0.70 \mathrm{~s}$, with a median value of $0.65 \mathrm{~s}$. This implies, as is evident from the timeseries, that the bubble plume from the preceding waves had not entirely dissipated before the second and third wave in a group broke. This observation is consistent with the finding described in detail below that the correlation of whitecap coverage with the corresponding brightness temperature increase for the first wave was greater than the corresponding correlation for either of the second or third waves in a group.

Day-to-day uniformity in the large-scale features of the wave field that controlled breaking process was verified using the wave heights measured by the pressure transducers. Significant wave height, $H_{1 / 3}$, is defined as the average height of the largest one-third of the waves. For deep-water waves $H_{1 / 3}$ can be estimated as four times the square root of the variance of the wave height, $\eta(t)$. The waves in the wave basin behaved approximately like deep-water waves for the deepest pressure trans- ducer, and therefore this relationship was used to estimate $H_{1 / 3}$ from the time-series for $\eta(t)$. Over a three-day measurement period, $H_{1 / 3}$ was found to be $34 \pm 1 \mathrm{~cm}, 29 \pm 3 \mathrm{~cm}$, and $29 \pm$ $3 \mathrm{~cm}$ on the respective days. Fig. 10 shows wave height spectral density estimates for these same three days. The major peak at a frequency of $0.56 \mathrm{~Hz}$ is the dominant wave frequency at the wavemaker paddle frequency. The origin of the second, lower frequency component is unknown, but as seen in the spectra it was reproducible from day-to-day and was likely responsible for the grouping behavior of the waves. Overall, the wave height information demonstrates that the large-scale features of the wave field were reproducible from day-to-day. The difference in wave spectral energy densities at frequencies above $1 \mathrm{~Hz}$ are due to wind-driven small-scale waves and do not affect the large-scale breaking.

As is evident in Fig. 9, breaking waves in this experiment occurred in groups of three over a duration of 5-6 s, with delays of 2-3 s between the groups of breaking waves. Fig. 11 shows a time-series of radiometric brightness temperatures and foam fraction observed at an azimuth angle of $0^{\circ}$ and an incidence angle of $53^{\circ}$. The dotted and solid curves are the measured vertical and horizontal brightness temperatures, respectively, and the dashed curve is the foam fraction in the field of view.

Figs. 12 and 13 show that, for the first breaking wave in each group, increases in both $T_{h}$ and $T_{v}$ are highly correlated with the foam fraction observed for that breaking wave. However, 

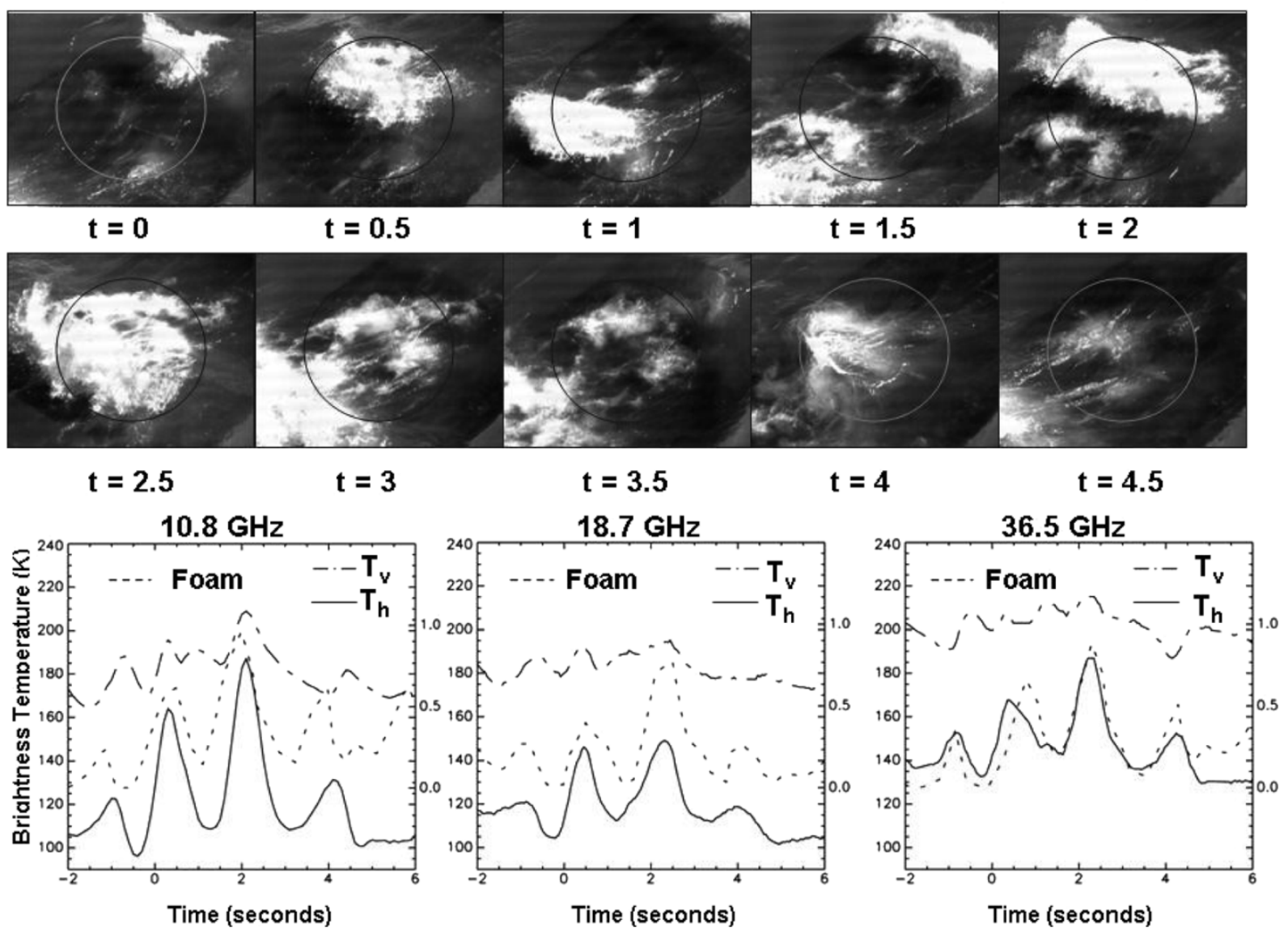

Fig. 15. Same as Fig. 14 except that the radiometers are viewing the breaking waves at an azimuth angle of $45^{\circ}$ and an incidence angle of $53^{\circ}$.

the correlation of increase in brightness temperature with foam fraction is significantly larger for $T_{h}$ than for $T_{v}$. This was found to be true for all azimuth angles as well as frequencies measured and is expected to be due to a combination of two physical effects. First, Rose et al. [7] show that the increase in surface emissivity between a calm, foam-free water surface and a foam-covered water surface is substantially larger for $T_{h}$ than $T_{v}$ in this range of incidence angles. Second, as each gravity wave steepens toward breaking in the field of view, the average local incidence angle decreases, leading to a decrease in $T_{v}$ and an increase in $T_{h}$. Therefore, as the wave begins to break, the increase in surface emission due to foam in $T_{v}$ is counteracted, and that in $T_{h}$ is enhanced, by the change in local incidence angle due to the long wave slopes.

Figs. 14-16 show three groups of breaking waves observed at an incidence angle of $53^{\circ}$, and at azimuth angles of $0^{\circ}, 45^{\circ}$, and $180^{\circ}$, respectively. The lower three plots in each figure show the measured vertical (dashed-dotted) and horizontal (solid) brightness temperatures as well as measured foam fraction in the field of view (dashed). The upper images show the collocated video images measured at a time interval of $0.5 \mathrm{~s}$. For example, Fig. 15 shows that the brightness temperature peaks at $t=0.5 \mathrm{~s}$ due to a wave breaking in the field of view. The second and third waves break in the field of view at $t=2.5$ and $t=4 \mathrm{~s}$, respectively. For all of the breaking wave measurements, the correlation coefficient between the increase in brightness temperature and the foam fraction in the field of view was found to be larger for the first breaking wave than for the second or third breaking waves. Brightness temperature increases due to the first breaking wave are expected to be more highly correlated with foam fraction because they occur at a time of minimum foam in the field of view (typically a foam fraction of less than 0.05) and are therefore less affected by residual foam and bubbles from previous breaking waves, consistent with the foam decay time measurements reported above. Therefore, only the first breaking wave in each group was analyzed to study the azimuthal dependence of the emissivity of foam and of foam fraction.

In order to calculate the increase in brightness temperatures due to breaking waves in the field of view, a baseline temperature, i.e., the brightness temperature of the water surface minimally affected by breaking waves, was needed. In each case, the baseline temperature, $T_{A, W}$ in (6c), was determined by finding the minimum measured brightness temperature during the 2-3-s delay between each group of breaking waves. This baseline brightness temperature was greater than the calm water brightness temperature by approximately 5 to $10 \mathrm{~K}$. The increase in brightness temperature at all three frequencies was calculated for the first breaking wave in each group at azimuth angles of $0^{\circ}, 45^{\circ}, 90^{\circ}$, and $180^{\circ}$. Figs. 17 and 18 show the increase in the brightness temperature of the surface due to foam, i.e., the product of $\epsilon_{\text {foam }}-\epsilon_{\text {rough_water }}$ from (6c) and $T_{W}$, as a function of the foam fraction in the 
$53^{\circ}$ incidence, $180^{\circ}$ azimuth

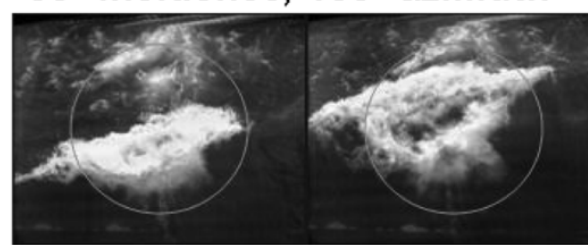

$\mathbf{t}=\mathbf{0}$

$\mathbf{t}=\mathbf{0 . 5}$

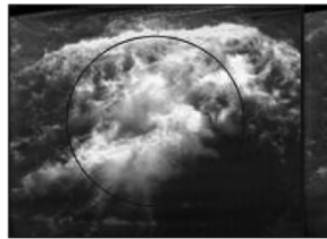

$\mathrm{t}=\mathbf{2 . 5}$

$10.8 \mathrm{GHz}$

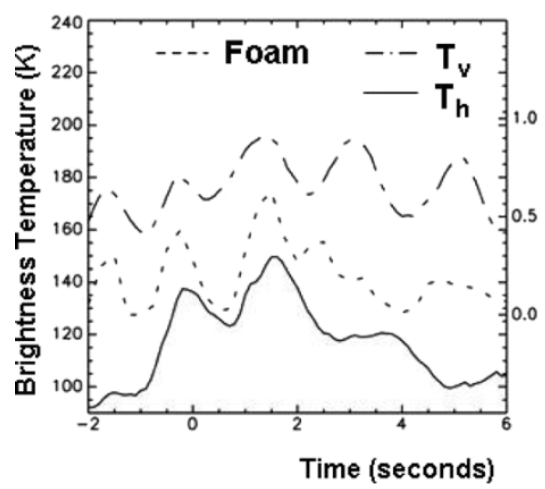

17 Oct 02 19:30:55 UT

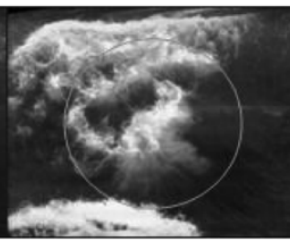

$t=1$

$t=1.5$

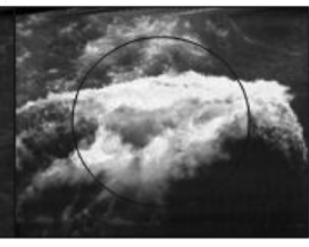

$\mathbf{t}=\mathbf{2}$
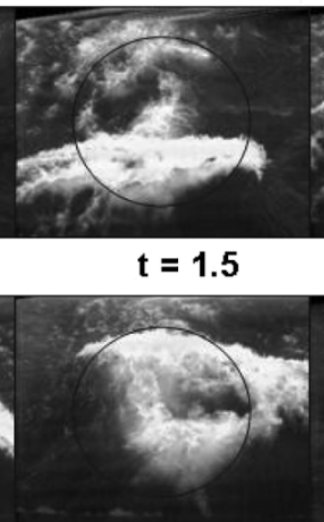

$t=4$

$\mathrm{t}=\mathbf{3 . 5}$

$18.7 \mathrm{GHz}$
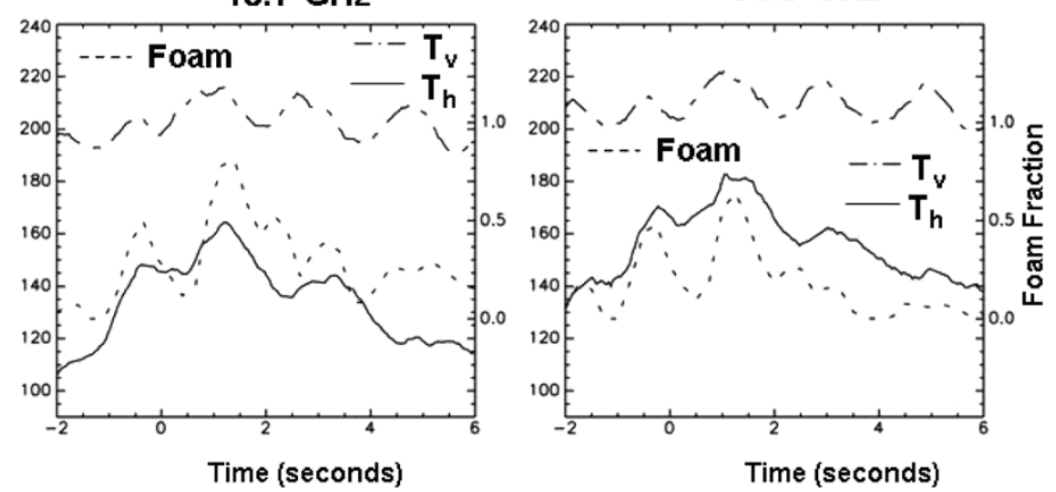

Fig. 16. Same as Fig. 14 except that the radiometers are viewing the breaking waves at an azimuth angle of $180^{\circ}$ and an incidence angle of $53^{\circ}$.

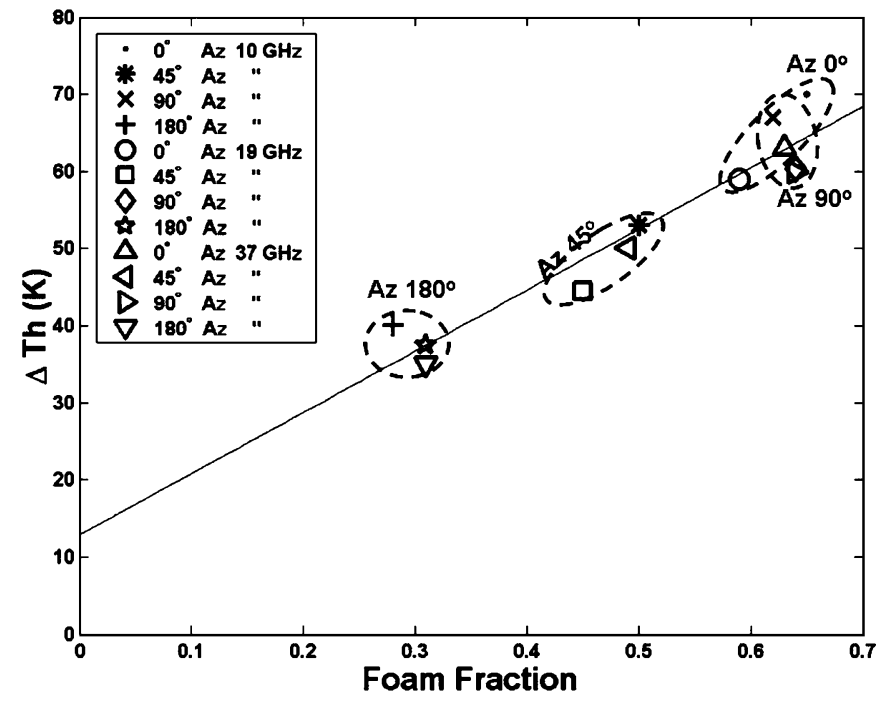

Fig. 17. Measured increase in horizontal brightness temperature due to foam for three different frequencies and at four azimuth angles, all at $53^{\circ}$ incidence angle.

field of view at all three frequencies and at horizontal and vertical polarizations.

A least squares linear fit was applied to the increase in brightness temperature as a function of foam fraction, as shown in Figs. 17 and 18. The fit parameters at both horizontal and vertical polarizations are provided in Table II. The increase

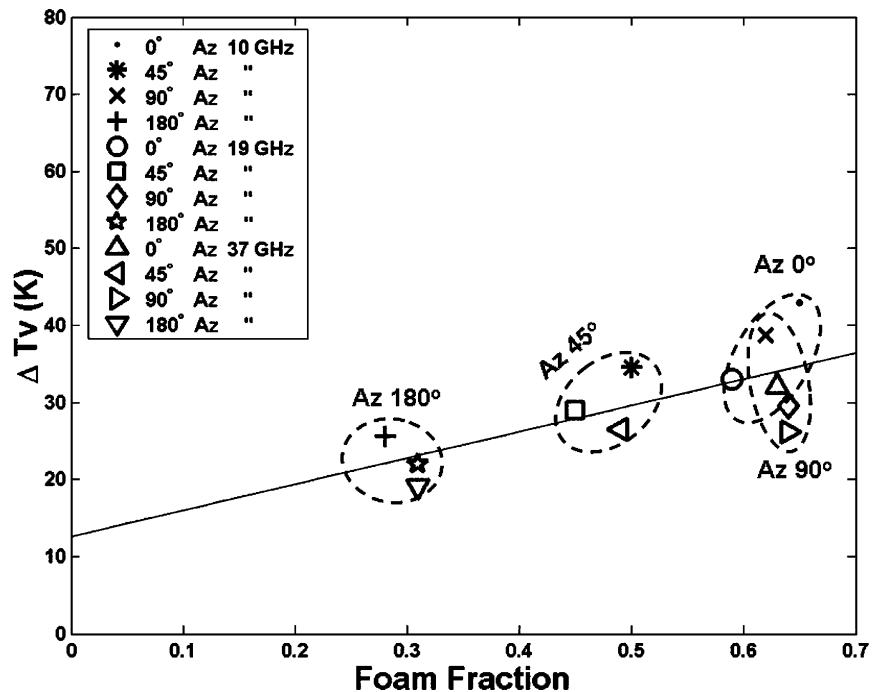

Fig. 18. Same as Fig. 17 except for vertical polarization.

TABLE II

LEAST SQUARES LiNEAR FIT TO THE INCREASE IN BRIGHTNESS TEMPERATURE AS A FUNCTION OF FOAM FRACTION

\begin{tabular}{|c|c|c|c|}
\hline Polarization & Slope & Intercept & Correlation Coefficient \\
\hline H-pol & 79.3 & 12.9 & 0.9 \\
\hline V-pol & 34 & 12 & 0.7 \\
\hline
\end{tabular}

in brightness temperature at $10.8 \mathrm{GHz}$ is greater than that at 18.7 or $37 \mathrm{GHz}$ for all azimuth angles, and the increase 


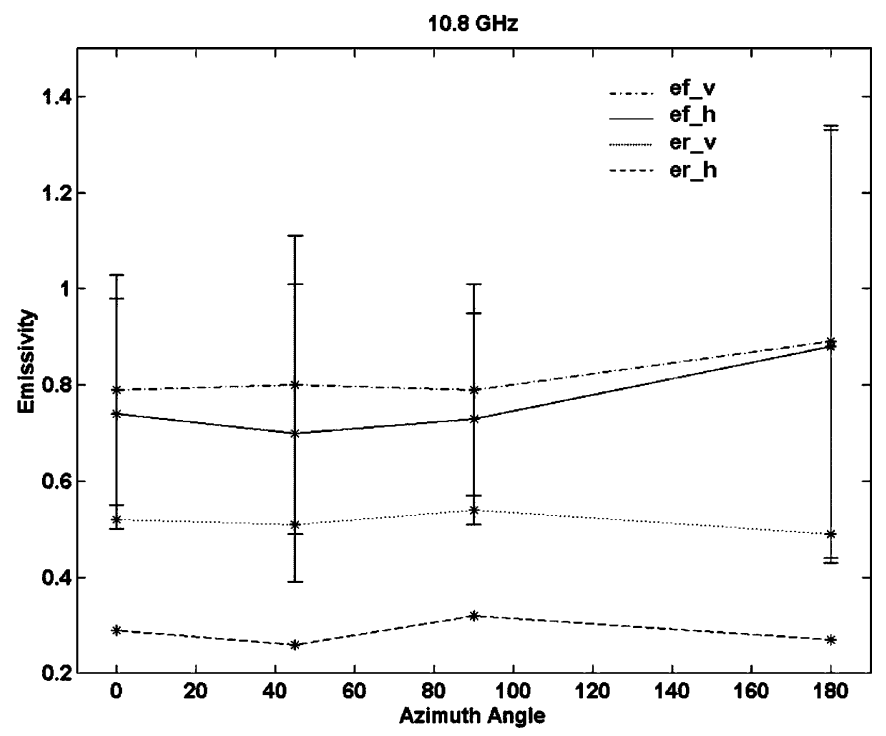

Fig. 19. Emissivity of foam and rough water at both horizontal and vertical polarizations as a function of azimuth angle at $10.8 \mathrm{GHz}$.

at $18.7 \mathrm{GHz}$ is in most cases greater than that at $37 \mathrm{GHz}$. Droppleman [21] has shown that for foam thickness greater than the electromagnetic wavelength and a high void fraction, foam emissivity should approach 1.0. Measurements of void fraction during POEWEX ' 02 using the shallower probe had peak values of $25 \%$ to $30 \%$. Foam thicknesses were expected to be larger than the penetration depth, causing measured foam emissivities to be similar at all three frequencies. Therefore, the change in emissivity from a foam-free surface to a partially foam-covered surface is expected to decrease with increasing frequency since the emissivities of calm water increase with frequency from 10.8 to $37 \mathrm{GHz}$ (e.g., Figs. 5 and 6, as well as [7]). Results shown in Figs. 17 and 18 are consistent with this expectation.

Figs. 19-21 show the emissivities of foam, $\epsilon_{\text {foam }}$, and rough water, $\epsilon_{\text {rough_water }}$ [from (6a) and (6b)] at both horizontal and vertical polarization as a function of azimuth angle at all three frequencies. The uncertainty in estimating whitecap coverage was found to be on the order of $\pm 10 \%$, which dominates the overall error and leads to values of uncertainty in the calculated emissivities on the order of \pm 0.3 , using [22]. However, the uncertainty associated with the radiometric data itself is substantially smaller, on the order of $\pm 0.6 \%$. The error bars shown in Figs. 19-21 indicate the range of the estimated emissivities, taking into account the uncertainties in both the whitecap coverage and radiometric data. However, it needs to be emphasized that their relatively large size is a consequence primarily of quantifying whitecap coverage rather than any difficulties in making precise radiometric measurements. As mentioned previously, the change in the brightness temperature from foamfree rough water to partially foam-covered rough water includes effects of both actively breaking crests and decaying bubble plumes. Wind speed and wind stress significantly affect the fraction of the sea surface covered by actively breaking crests and decaying bubble plumes. Wind stress, typically quantified as friction velocity, is theoretically more closely correlated with surface emissivity than wind speed is, but measurements have

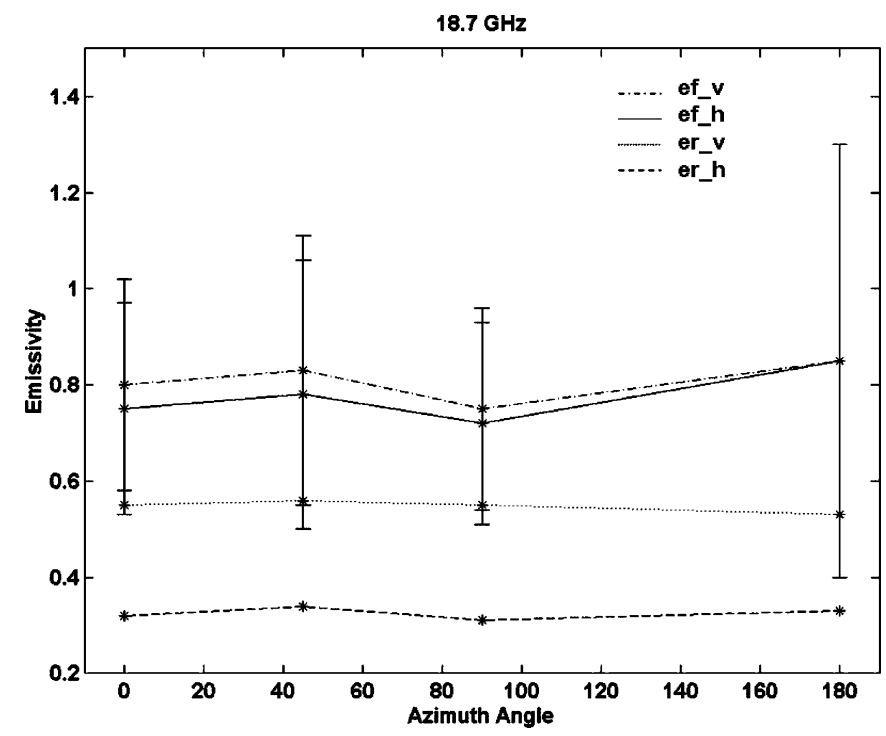

Fig. 20. Same as Fig. 19 except for $18.7 \mathrm{GHz}$.

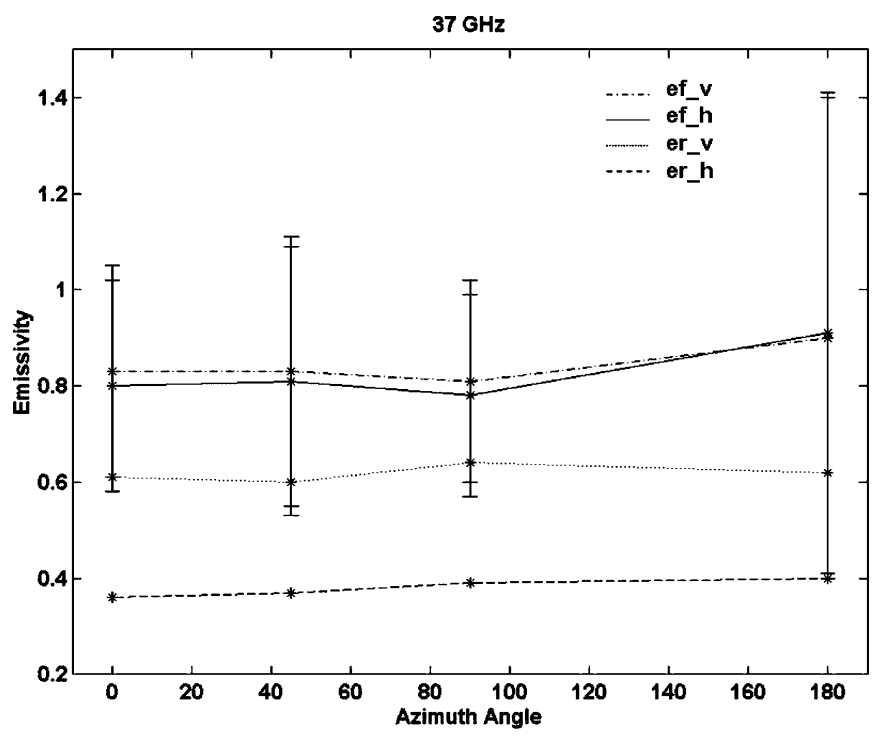

Fig. 21. Same as Fig. 19 except for $37 \mathrm{GHz}$.

shown similar correlations of the two parameters to microwave emissivity [11], and measurements of wind speed generally have smaller errors.

For low to moderate wind speeds, fractional-area whitecap coverage (i.e., the oceanic equivalent of fractional area foam coverage) has been parameterized as having a cubic dependence on wind speed [23]. Measurements of whitecap coverage were conducted at low to moderate wind speeds $(2-16 \mathrm{~m} / \mathrm{s})$ in a series of experiments from ships and the R/P FLIP using the method outlined by Asher et al. [24]. Stramska and Petelski [25] conducted similar measurements in the North Atlantic and separated their data into conditions of developed $(5-11 \mathrm{~m} / \mathrm{s})$ and undeveloped $(7-14 \mathrm{~m} / \mathrm{s})$ sea states. The developed sea state was chosen when the measured significant wave height exceeded a hypothetical wave height for a fully developed sea at the measured wind speed. They found that, for their measurements, the relationship of whitecap coverage to wind speed was not sensitive to water temperature or to atmospheric 
TABLE III

AZIMUTHALly AVERAGED INCREASE IN SURFACE BRIGHTNESS TEMPERATURES DUE TO FOAM FOR $100 \%$ COVERAGE

\begin{tabular}{|c|c|c|}
\hline Frequency & Horizontal Polarization (K) & Vertical Polarization (K) \\
\hline $10.8 \mathrm{GHz}$ & 131.5 & 82.2 \\
\hline $18.7 \mathrm{GHz}$ & 118.6 & 68.6 \\
\hline $37 \mathrm{GHz}$ & 117.4 & 60.1 \\
\hline
\end{tabular}

TABLE IV

UNCERTAINTIES IN PREDICTED BRIGHTNESS TEMPERATURE INCREASES FOR $100 \%$ FOAM COVERAGE

\begin{tabular}{|c|c|c|}
\hline Frequency & $T_{H}$ uncertainty $(\mathrm{K})$ & $T_{V}$ uncertainty $(\mathrm{K})$ \\
\hline $10.8 \mathrm{GHz}$ & 7.8 & 5.6 \\
\hline $18.7 \mathrm{GHz}$ & 4.6 & 3.4 \\
\hline $37 \mathrm{GHz}$ & 4.2 & 3.3 \\
\hline
\end{tabular}

stability. During WISE 2001 (Wind and Salinity Experiment 2001) in the northern Mediterranean Sea, whitecap coverage was measured as a function of wind speed $(3-18 \mathrm{~m} / \mathrm{s})$ [26]. These four sets of measurements of whitecap coverage and wind speed provide four separate estimates (i.e., one from Asher et al. [24], two from Stramska and Petelski [25], and one from Camps et al. [26]) of the empirical constants in the Monahan and $\mathrm{Lu}$ model [23]. These four parameterizations of whitecap coverage with wind speed were used to estimate the increase in brightness temperatures due to foam measured by a satellite microwave radiometer. To do this, the same $\epsilon_{\text {foam }}-\epsilon_{\text {rough_water }}$ used to compute the measured brightness temperature increases shown in Figs. 17 and 18 were azimuthally averaged and converted to increases in surface emission between a foam-free rough water surface and a $100 \%$ foam-covered rough water surface by assuming $\eta=1$ and computing $\left(\epsilon_{\text {foam }}-\epsilon_{\text {rough_water }}\right)\left(T_{W}-T_{A, \mathrm{SKY}}\right)$. The results are listed in Table III for all measured frequencies at horizontal and vertical polarizations. Error analysis yields uncertainties in brightness temperature increases from a foam-free surface to a $100 \%$ foam-covered surface, due only to the error in the radiometric measurements. These uncertainties in brightness temperature increases for $100 \%$ whitecap coverage are shown in Table IV. The brightness temperature increase for $100 \%$ foam coverage is multiplied by the whitecap coverage predicted by the four different parameterizations of whitecap coverage listed above [24]-[26] to obtain predicted increases in brightness temperature due to breaking waves in the field of view of a satellite microwave radiometer at $53^{\circ}$ incidence angle at $10.8 \mathrm{H}, 10.8 \mathrm{~V}, 36.5 \mathrm{H}$, and $36.5 \mathrm{~V}$ as a function of wind speed, as shown in Figs. 22-25, respectively. To compare with an independent model, the Wilheit model [27] of the increase in surface emission due to breaking waves is plotted in Figs. 22-25 as a function of wind speed. He considered this increase to be independent of polarization and proportional to the amount that the wind speed exceeds $7 \mathrm{~m} / \mathrm{s}$, approximately the onset of wave breaking. The Wilheit model curve shows the predicted increase in brightness temperature for the values of $T_{W}$ and $T_{A, \mathrm{SKY}}$ measured during POEWEX'02.

The fact that these different models of whitecap coverage and of brightness temperature increase lead to vastly different changes in brightness temperature due to breaking waves shows that the whitecap coverage problem is not well understood. Different sets of measurements may lead to different whitecap cov-

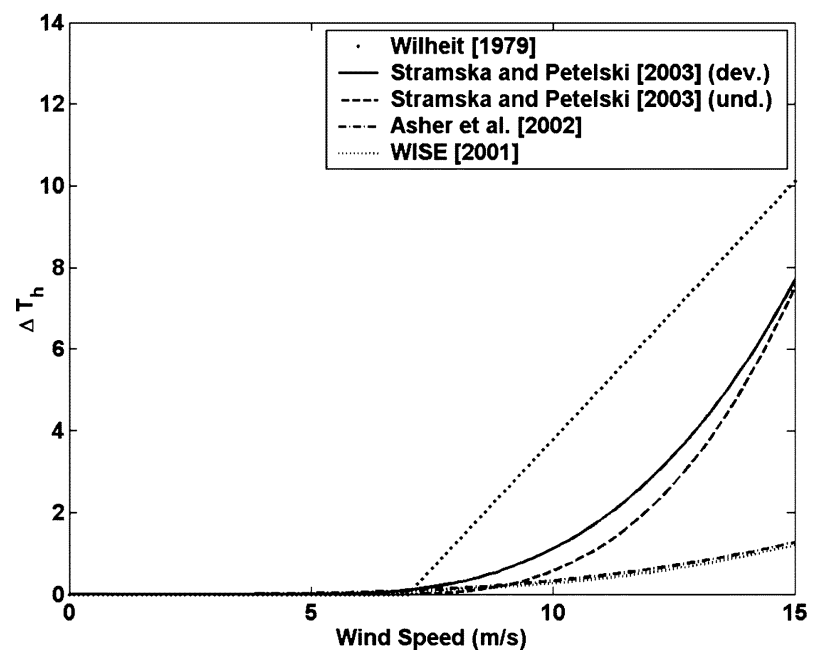

Fig. 22. Increase in horizontal brightness temperatures at $10.8 \mathrm{GHz}$ expected to be measured by a satellite radiometer at low to moderate wind speeds.

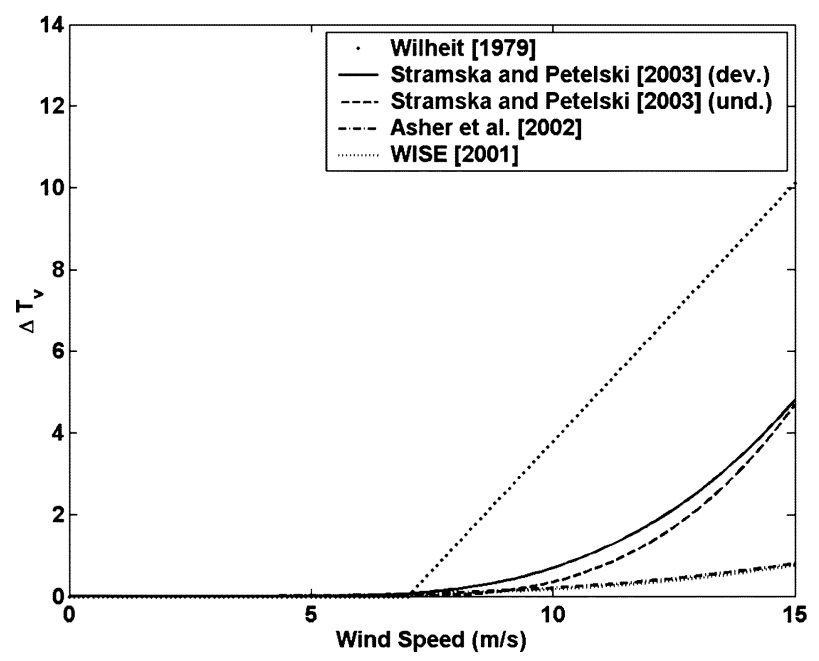

Fig. 23. Same as Fig. 22 except for vertical brightness temperatures at $10.8 \mathrm{GHz}$

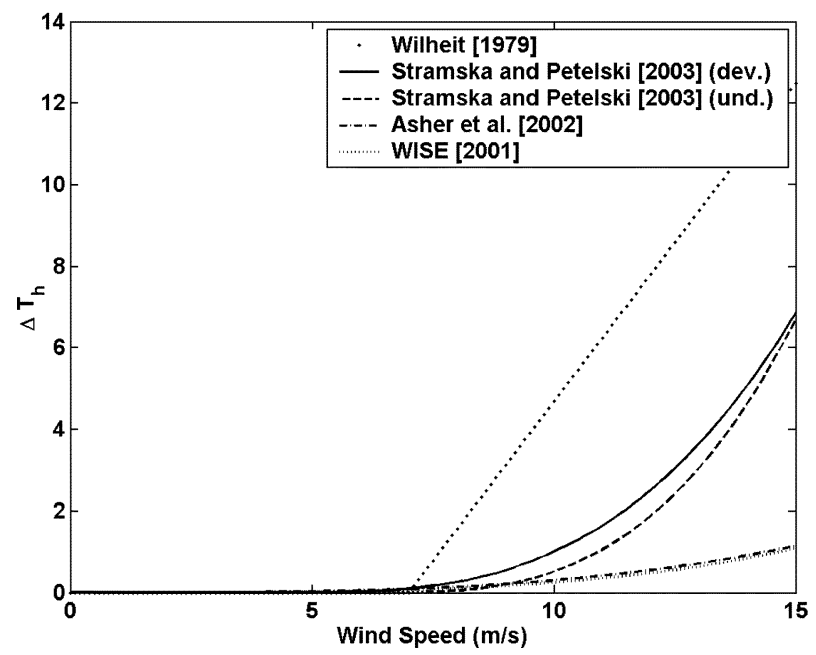

Fig. 24. Same as Fig. 22 except for horizontal brightness temperatures at $37 \mathrm{GHz}$.

erages due to variability in sea state conditions such as fetch, currents and interaction of waves with swell. More measure- 


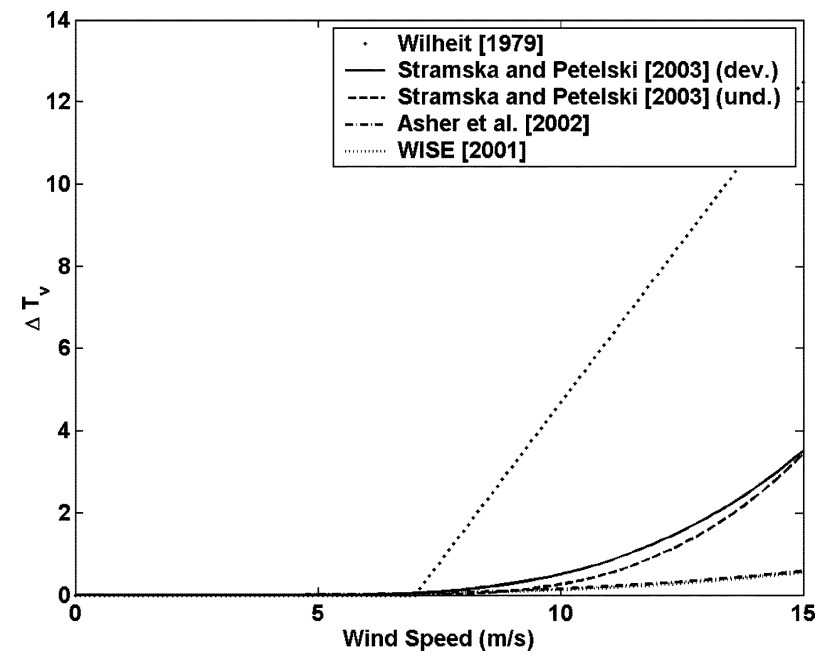

Fig. 25. Same as Fig. 22 except for vertical brightness temperatures at $37 \mathrm{GHz}$.

ments of whitecap coverage are needed to obtain parameterizations that are applicable to a wide range of sea states.

\section{CONCLUSION}

Results of the FAIRS measurements from the R/P FLIP in the northeastern Pacific Ocean indicate that the increase in microwave emission due to breaking waves on the open ocean depends on the incidence and azimuth angles of observation. Since breaking waves on the open ocean are temporally intermittent and highly variable in terms of location and size, radiometric measurements of reproducible breaking waves were performed in a saltwater wave basin to study systematically the effects of incidence and azimuth angle variation. During the POEWEX'02 experiment, concurrent measurements were performed of the microwave emission from foam generated by reproducible breaking waves at X-, K-, and Ka-bands and of the foam fraction in the fields of view of the radiometers. In addition, in situ measurements were performed to measure the void fraction and bubble size spectrum of foam, as well as the wave height spectrum. These physical measurements were used to verify that the gross features of breaking waves in the wave tank were similar to those on the open ocean.

Results of the POEWEX'02 experiment were used to estimate the effect of breaking waves and foam on brightness temperatures measured by a satellite microwave radiometer at low to moderate wind speeds. Measurements of whitecap coverage with respect to wind speed provide empirical fit parameters to the Monahan and $\mathrm{Lu}$ model for foam coverage. Since the WindSat accuracy requirement for wind direction is $\pm 20^{\circ}$ over $3-25 \mathrm{~m} / \mathrm{s}$, even a large wind direction signal at these frequencies of $3 \mathrm{~K}$ peak-to-peak requires brightness temperature accuracy of better than $0.2 \mathrm{~K}$. Therefore, from Figs. $22-25$, the increase in brightness temperatures due to breaking waves and foam is expected to significantly affect wind direction retrievals at or above $5-\mathrm{m} / \mathrm{s}$ wind speed. The effect of foam on brightness temperatures was shown to vary with azimuth angle. As a quantitative example, for the Stramska and Petelski model of whitecap coverage at a wind speed of 15 $\mathrm{m} / \mathrm{s}$, the increase in the brightness temperatures measured by a spaceborne radiometer due to breaking waves is expected to be approximately 4.5 and $7.5 \mathrm{~K}$ at $10.8 \mathrm{GHz}$, and 3.5 and $7 \mathrm{~K}$ at $37 \mathrm{GHz}$, at vertical and horizontal polarization, respectively, a significant variation with frequency.

The POEWEX'02 measurements demonstrate that a number of additional physical parameters are required to obtain an accurate quantitative estimate of the azimuthal variation of the microwave emission from foam generated by breaking waves, in addition to the radiometric brightness temperature and foam fraction in the field of view. Further work needs to be performed to develop robust algorithms for extracting whitecap coverage from sea surface imagery. Knowledge of the wave slope spectrum during wave breaking is required to characterize more fully the effects of the wave field and sea state on the increase in emission between a foam-free rough water surface and a foamcovered rough water surface. Finally, analysis of radiometric time-series from the POEWEX'02 experiment showed that it is important to measure not only foam-free calm water but also foam-free rough water over a substantial period of time with no breaking waves in the field of view.

\section{ACKNOWLEDGMENT}

The authors thank K. Horgan (now at NASA/GSFC), N. Allan (now at AFRL/Hanscom AFB), and the crew of the R/P FLIP at the Marine Physical Laboratory of the Scripps Institute of Oceanography for their substantial contributions to the FAIRS measurements in 2000.

\section{REFERENCES}

[1] P. W. Gaiser, K. M. St. Germain, E. M. Twarog, G. A. Poe, W. Purdy, D. Richardson, W. Grossman, W. L. Jones, D. Spencer, G. Golba, J Cleveland, L. Choy, R. M. Bevilacqua, and P. S. Chang, "The WindSat spaceborne polarimetric microwave radiometer: Sensor description and early orbit performance," IEEE Trans. Geosci. Remote Sens., vol. 42, no. 11, pp. 2347-2361, Nov. 2004.

[2] S. Yueh, W. J. Wilson, F. K. Li, W. Ricketts, and S. V. Ngheim, "Polarimetric microwave brightness signatures of ocean wind directions," IEEE Trans. Geosci. Remote Sens., vol. 37, no. 2, pp. 949-959, Mar. 1999.

[3] J. R. Piepmeier and A. J. Gaisiewski, "High-resolution passive polarimetric microwave mapping of ocean surface wind vector fields," IEEE Trans. Geosci. Remote Sens., vol. 39, no. 3, pp. 606-622, Mar. 2001.

[4] G. A. Wick, J. J. Bates, and C. C. Gottschall, "Observational evidence of a wind direction signal in SSM/I passive microwave data," IEEE Trans. Geosci. Remote Sens., vol. 38, no. 2, pp. 823-837, Mar. 2000.

[5] T. Meissner and F. Wentz, "An updated analysis of the ocean surface wind direction signal in passive microwave brightness temperature," IEEE Trans. Geosci. Remote Sens., vol. 40, no. 6, pp. 1230-1240, Jun. 2002.

[6] F. J. Wentz, “A well calibrated ocean algorithm for SSM/I," J. Geophys. Res., vol. 102, no. C4, pp. 8703-8718, Apr. 1997.

[7] L. A. Rose, W. E. Asher, S. C. Reising, P. W. Gaiser, K. M. St. Germain, D. J. Dowgiallo, K. A. Horgan, G. Farquharson, and E. J. Knapp, "Radiometric measurements of the microwave emissivity of foam," IEEE Trans. Geosci. Remote Sens., vol. 40, no. 12, pp. 2619-2625, Dec. 2002.

[8] D. Chen, L. Tsang, L. Zhou, S. C. Reising, W. Asher, L. A. Rose, K. H. Ding, and C.-T. Chen, "Microwave emission and scattering of foam based on Monte Carlo simulations of dense media," IEEE Trans. Geosci. Remote Sens., vol. 41, no. 4, pp. 782-790, Apr. 2003.

[9] W. E. Asher, A. T. Jessup, and M. A. Atmane, "Oceanic application of the active controlled flux technique for measuring air-sea transfer velocities of heat and gases," J. Geophys. Res.-Oceans, vol. 109, no. C8, Aug. 2004. Article no. C08S12.

[10] S. C. Reising, W. E. Asher, L. A. Rose, and M. A. Aziz, "Passive polarimetric remote sensing of the ocean surface: the effects of surface roughness and whitecaps," presented at the 27th URSI General Assembly, Int Union of Radio Science, Maastrict, Netherlands, Aug. 2002. 
[11] M. A. Aziz, S. C. Reising, W. E. Asher, L. A. Rose, P. W. Gaiser, and K. A. Horgan, "Effects of air-sea interaction parameters on ocean surface microwave emission at 10 and $37 \mathrm{GHz}$, " IEEE Trans. Geosci. Remote Sens., vol. 43, no. 8, pp. 1763-1774, Aug. 2005.

[12] S. Padmanabhan and S. C. Reising, "Radiometric measurements of microwave emissivity of reproducible breaking waves," in Proc. IGARSS, Toulouse, France, Jul. 2003, pp. 410-412.

[13] W. E. Asher and R. Wanninkhof, "The effect of bubble mediated gas transfer on purposeful dual gaseous experiments," J. Geophys. Res., vol. 103, no. 10, pp. 555-560, May 1998.

[14] E. Lamarre and W. K. Melville, "Instrumentation for the measurement of void-fraction in breaking waves - Laboratory and field results," IEEE J. Oceanic Eng., vol. 17, no. 2, pp. 204-215, Apr. 1992.

[15] R. G. Dean and R. A. Dalrymple, Water Wave Mechanics for Scientists and Engineers, Singapore: World Scientific, Jan. 1991, p. 353.

[16] L. A. Klein and C. T. Swift, "An improved model for the dielectric constant of sea water at microwave frequencies," IEEE Trans. Antennas Propagat., vol. AP-25, no. 1, pp. 104-111, Jan. 1977.

[17] W. Ellison, A. Balana, G. Delbos, K. Lamkaouchi, L. Eymard, C. Guillou, and C. Prigent, "New permittivity measurements of seawater," Radio Sci., vol. 33, no. 3, pp. 639-648, May-Jun. 1998.

[18] G. B. Deane and M. D. Stokes, "Scale dependence of bubble creation mechanisms in breaking waves," Nature, vol. 418, pp. 839-844, Aug. 2002.

[19] E. Lamarre and W. K. Melville, "Void-fraction measurements and sound-speed fields in bubble plumes generated by breaking waves," $J$. Acoust. Soc. Amer., vol. 95, no. 3, pp. 1317-1328, Mar. 1994.

[20] G. B. Deane, "Sound generation and air entrainment by breaking waves in the surf zone," J. Acoust. Soc. Amer., vol. 102, no. 5, pp. 2671-2689, Nov. 1997.

[21] J. D. Droppleman, "Apparent microwave emissivity of sea foam," $J$. Geophys. Res., vol. 75, no. 3, pp. 696-698, Jan. 1970.

[22] J. R. Taylor, An Introduction to Error Analysis. Sausalito, CA: University Science Books, 1997.

[23] E. C. Monahan and M. Lu, "Acoustically relevant bubble assemblages and their dependence on meteorological parameters," IEEE J. Oceanic Eng., vol. 15, no. 4, pp. 340-349, Oct. 1990.

[24] W. E. Asher, J. B. Edison, W. R. McGillis, R. Wanninkhof, D. T. Ho, and T. Litchendorf, "Fractional area whitecap coverage and air-sea gas transfer during GasEx-98," in Gas Transfer at Water Surfaces. ser. Geophysics Monographs, M. A. Donelan et al., Ed. Washington, DC: AGU, 2002, vol. 127, pp. 199-204.

[25] M. Stramska and T. Petelski, "Observations of oceanic whitecaps in the north polar waters of the Atlantic," J. Geophys. Res., vol. 108, no. C3, pp. 31-1-31-10, Mar. 2003.

[26] A. Camps, J. Font, M. Vall-Illossera, C. Gabarro, I. Corbella, N. Duffo, F. Torres, S. Blamch, A. Aguasca, R. Villarino, L. Enrique, J. J. Miranda, J. J. Arenas, A. Julia, J. Etcheto, V. Caselles, A. Weil, J. Boutin, S. Contardo, R. Niclos, R. Rivas, S. C. Reising, P. Wursteisen, M. Berger, and M. Martin-Neira, "The WISE 2000 and 2001 field experiments in support of the SMOS mission: Sea surface L-band brightness temperature observations and their application to sea surface salinity retrieval," IEEE Trans. Geosci. Remote Sens., vol. 42, no. 4, pp. 804-823, Apr. 2004.

[27] T. Wilheit, "A model for the microwave emissivity of the ocean's surface as a function of wind speed," IEEE Trans. Geosci. Remote Sens., vol. GE-17, no. 4, pp. 244-249, Oct. 1979.

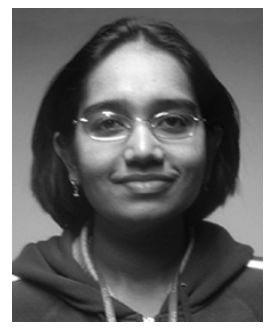

Sharmila Padmanabhan (S'02) received the B.Eng. degree in electronics and telecommunications engineering from the University of Mumbai, Mumbai, India, and the M.S degree in electrical and computer engineering from the University of Massachusetts, Amherst, in 2001 and 2004, respectively. She is currently pursuing the Ph.D. degree at Colorado State University, Fort Collins. Her Master's research focused on design, testing, calibration, and data analysis for a K-band polarimetric radiometer at the Microwave Remote Sensing Laboratory, University of Massachusetts Amherst.

Ms. Padmanabhan received a Young Scientist Award at the URSI General Assembly in New Delhi, India, in 2005. While at UMass, she received second place in the IEEE Geoscience and Remote Sensing Student Paper Competition at IGARSS 2003 in Toulouse, France.

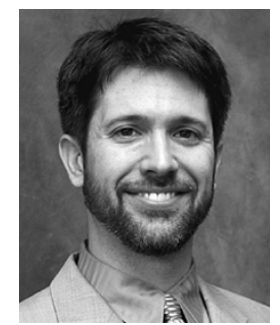

Steven C. Reising (S'88-M'98-SM'04) received the B.S.E.E. (magna cum laude) and M.S.E.E. degrees in electrical engineering from Washington University, St. Louis, MO, in 1989 and 1991, respectively, and the Ph.D. degree from Stanford University, Stanford, CA, in 1998, where he was advised by Prof. Umran S. Inan and supported by a NASA Earth Systems Science Fellowship. At Stanford, his research focused on low-frequency remote sensing of lightning and its energetic coupling to the ionosphere, which produces chemical changes and transient optical emissions.

From 1998 to 2004, he was an Assistant Professor in electrical and computer engineering at the University of Massachusetts, Amherst. During the summers of 1999, 2000, and 2003, he was a Summer Faculty Fellow in the Remote Sensing Division, Naval Research Laboratory, Washington, DC. In September 2004, he became an Associate Professor in electrical and computer engineering at Colorado State University, Fort Collins. His research interests are passive microwave and millimeter-wave remote sensing of the oceans, atmosphere, and land, including polarimetric radiometer systems and technology. He has served as a reviewer for Radio Science, Geophysical Research Letters, and the Journal of Oceanography.

Dr. Reising received the NSF CAREER Award (2003-2008) and the Office of Naval Research Young Investigator Program (YIP) Award (2000-2003). He was awarded the Barbara H. and Joseph I. Goldstein Outstanding Junior Faculty Award in 2004, the Lilly Teaching Fellowship for 2001-2002, and a Young Scientist Award at the URSI General Assembly in Toronto, Canada, in 1999. While at Stanford, he received first place in the USNC/URSI Student Paper Competition at the 1998 National Radio Science Meeting in Boulder, CO. He serves an Associate Editor of IEEE GEOSCIENCE AND REMOTE SENSING LETTERS. He serves as an elected member of the IEEE Geoscience and Remote Sensing Society's (GRSS) Administrative Committee (2003-2008) and is currently the Membership Chair. He served the IEEE GRSS Newsletter as Editor from April 2000 to March 2003 and as Associate Editor for University Profiles from 1998 to 2000. He was the Chair of the Springfield, Massachusetts Joint Chapter of the IEEE AP, GRS, ED, MTT, and LEO Societies (1999-2004) and has been a member of the Technical Program Committee of every IGARSS from 2001 to present. He will chair the Specialist Meeting on Microwave Radiometry and Remote Sensing Applications, MicroRAD '06, in San Juan, Puerto Rico. He chairs the annual USNC International Union of Radio Science (URSI) Student Paper Competition in Boulder, CO (2004-present). He is a member of URSI Commissions F, G, and $\mathrm{H}$, and is the Secretary of USNC/URSI Commission F (2006-2008). He has served as a reviewer for the IEEE TRANSACTIONS on Geoscience And Remote Sensing and IEEE Geoscience AND Remote SENSING LETTERS. He is a member of the American Meteorological Society, the American Geophysical Union, Tau Beta Pi, and Eta Kappa Nu.

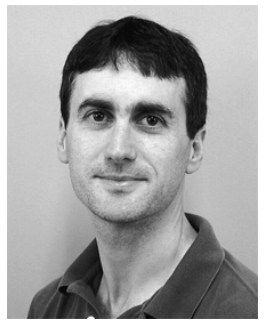

William E. Asher (M'05) received the B.A. degree in chemistry from Reed College, Portland, OR, and the $\mathrm{Ph} . \mathrm{D}$. degree in environmental science and engineering from Oregon Graduate Institute for Science and Technology, Beaverton, OR, in 1980 and 1987, respectively.

He is currently a Senior Oceanographer at the Applied Physics Laboratory, University of Washington, Seattle, and a Staff Scientist at the Department of Environmental Science and Engineering, Oregon Health and Sciences University, Beaverton. His research interests include characterization of breaking waves, air-sea transfer processes, and modeling the formation of secondary organic aerosols. He has been an Associate Editor for the Journal of Geophysical Research-Oceans (American Geophysical Union) and an editor for Atmospheric Chemistry and Physics (European Geophysical Society). 


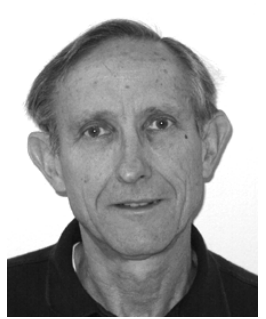

L. Allen Rose (S'60-M'61) received the B.S.E.E. degree from the University of Arkansas, Fayetteville, the M.S. degree in physics from Vanderbilt University, Nashville, TN, and the Ph.D. degree in astrophysics from the University of Minnesota, Minneapolis.

$\mathrm{He}$ is currently a Research Physicist in the Microwave Remote Sensing Section, Remote Sensing Division, Naval Research Laboratory, Washington, DC. He prepared a suite of SSM/I simulator radiometers and conducted a series of NRL RP-3A aircraft underflight measurements in support of the Navy's initial calibration of the DMSP SSM/I passive microwave sensors. He has performed many field and aircraft experiments to study the emission of microwave radiation from land and ocean surfaces.

Dr. Rose is a member of the American Astronomical Society and the American Geophysical Union.

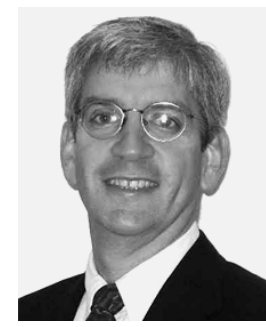

Peter W. Gaiser (S'91-M'93-SM'04) received the B.S. degree in electrical engineering from Virginia Polytechnic Institute and State University, Blacksburg, in 1987, and the Ph.D. degree from the University of Massachusetts, Amherst, in 1993 where he studied microwave remote sensing, with emphasis on synthetic aperture interferometric radiometry.

He has been with the Naval Research Laboratory (NRL), Washington, DC, since 1993, and currently Acting Head of the Remote Sensing Physics Branch, Remote Sensing Division at NRL. While at NRL, he has been involved in polarimetric radiometry research. His research interests also include instrument design, data collection, and model development specifically for the purpose of ocean wind vector measurements from space. He is the Principal Investigator for the WindSat spaceborne polarimetric microwave radiometer demonstration project. 